Florida International University FIU Digital Commons

\title{
Help Me Chat: Eliciting Communicative Acts from Young Children Using Speech-Generating Devices
}

Rebecca A. Hernandez-Cartaya

Florida International University, rhern233@fiu.edu

DOI: $10.25148 /$ etd.FIDC000782

Follow this and additional works at: https://digitalcommons.fiu.edu/etd

Part of the Speech Pathology and Audiology Commons

\section{Recommended Citation}

Hernandez-Cartaya, Rebecca A., "Help Me Chat: Eliciting Communicative Acts from Young Children Using Speech-Generating Devices" (2016). FIU Electronic Theses and Dissertations. 2538.

https://digitalcommons.fiu.edu/etd/2538 


\section{FLORIDA INTERNATIONAL UNIVERSITY}

Miami, Florida

\section{HELP ME CHAT:}

\section{ELICITING COMMUNICATIVE ACTS FROM YOUNG CHILDREN USING \\ SPEECH-GENERATING DEVICES}

A thesis submitted in partial fulfillment of

the requirements for the degree of

MASTER OF SCIENCE

in

SPEECH LANGUAGE PATHOLOGY

by

Rebecca Hernandez-Cartaya

2016 
To: Dean Ora L. Strickland

College of Nursing and Health Sciences

This thesis, written by Rebecca Hernandez-Cartaya, and entitled Help Me Chat: Eliciting Communicative Acts from Young Children Using Speech-Generating Devices, having been approved in respect to style and intellectual content, is referred to you for judgement.

We have read this thesis and recommend that it be approved.

Alfredo Ardila

Monica Hough

Eliane Ramos, Major Professor

Date of Defense: July 8, 2016

The thesis of Rebecca Hernandez-Cartaya is approved.

Ora L. Strickland College of Nursing and Health Sciences

Andrés G. Gil

Vice President for Research and Economic Development and Dean of the University Graduate School

Florida International University, 2016 
C Copyright 2016 by Rebecca Hernandez-Cartaya

All rights reserved. 


\section{DEDICATION}

For the children and adults for whom the desire to communicate overcomes all obstacles.

I may help you chat, but you have taught me so much more about the right and privilege of human communication. 


\section{ACKNOWLEDGMENTS}

I would like to thank the members of my committee for their time and guidance in steering this thesis to fruition. Special thanks to my major professor, Dr. Eliane Ramos, whose gentle but purposeful assistance was instrumental to the meaningful completion of this study. I am deeply thankful to Dr. Michelle Schladant for introducing to me to the dynamic world of $\mathrm{AAC}$, and for making the abstract concept of research a reality and Dr. Monica Dowling, whose keen insights and precision of thought deeply inform this paper. Lastly, I want to acknowledge my family, without whom my abilities to both analyze and impact the world around us would be markedly reduced. Thank you all for your contributions to this project. 
ABSTRACT OF THE THESIS

\title{
HELP ME CHAT: ELICITING COMMUNICATIVE ACTS FROM YOUNG CHILDREN USING SPEECH-GENERATING DEVICES
}

\author{
by \\ Rebecca Hernandez-Cartaya \\ Florida International University, 2016 \\ Miami, Florida \\ Professor Eliane Ramos, Major Professor
}

\begin{abstract}
Augmentative and alternative communication (AAC) is an evidence-based practice targeting the communication deficits of children with complex communication needs (CCN). While young children with communication disorders are attending preschool and using AAC, and specifically speech-generating devices (SGDs), with increasing frequency, best practices for implementation with this population are largely unexplored. In an effort to contribute to the knowledge base for teachers, the essential communication partners for children in the classroom setting, this research explored the interactions of four teacher-child dyads and analyzed the prompts and cues used to elicit communicative acts from the children.
\end{abstract}

Results of statistical and descriptive analyses revealed that, while teachers overwhelmingly favor and use verbal prompts over other stimuli, these prompts were no more effective in eliciting communicative acts. These results indicate that teachers would benefit from instruction in a variety of techniques for enhancing communication via AAC; future research directions towards this purpose are detailed. 
CHAPTER

PAGE

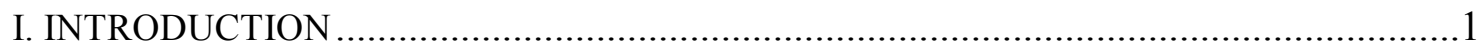

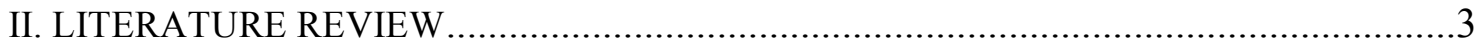

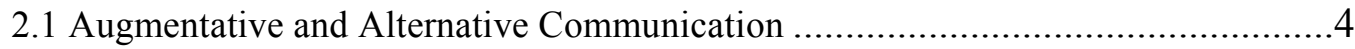

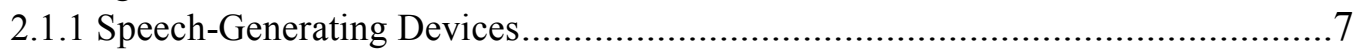

2.2 Children with Complex Communication Needs ...............................................

2.2.1 Indications of AAC/SGDs for Children with $\mathrm{CCN}$.......................................11

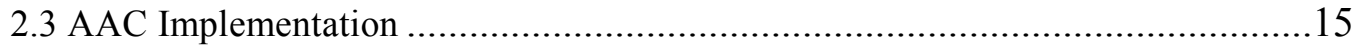

2.3.1 AAC Implementation in Classrooms/The Teacher's Role ............................19

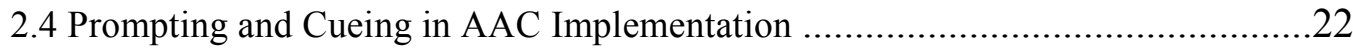

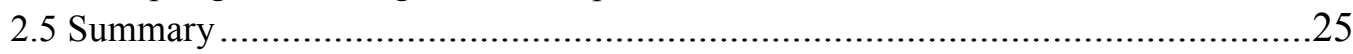

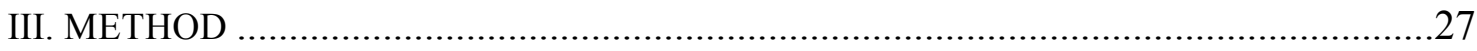

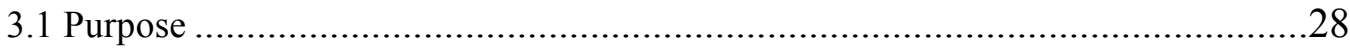

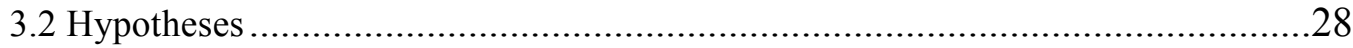

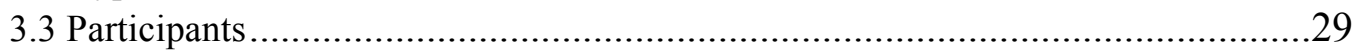

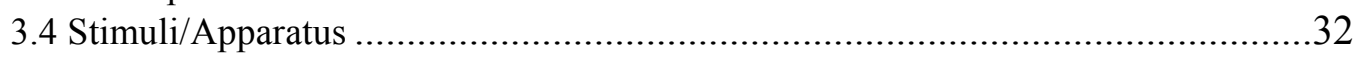

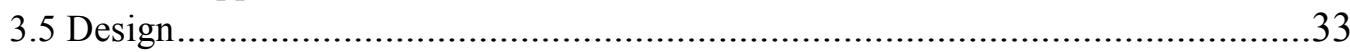

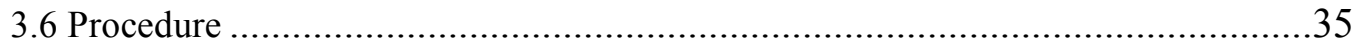

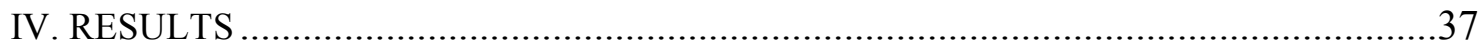

V. DISCUSSION

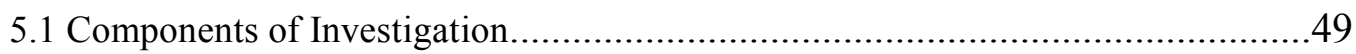

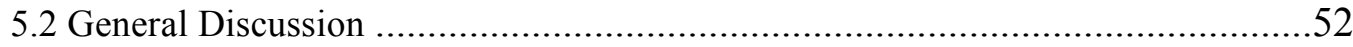

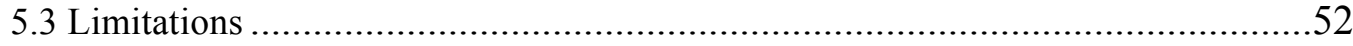

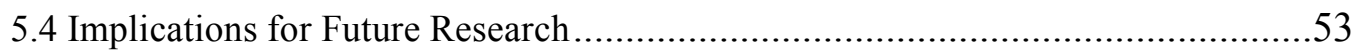

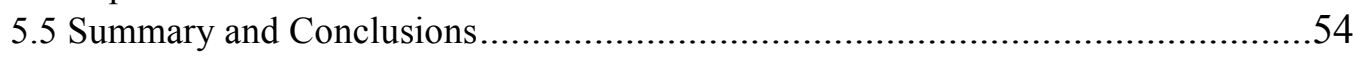

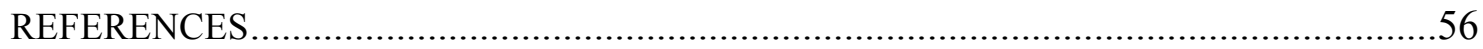

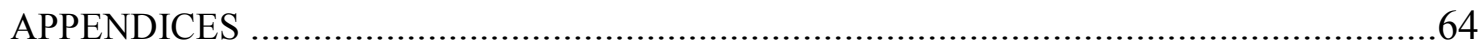




\section{LIST OF FIGURES}

FIGURE

PAGE

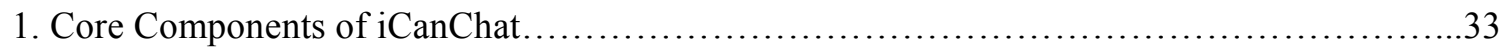

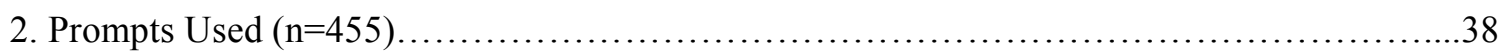

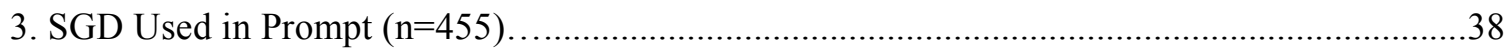

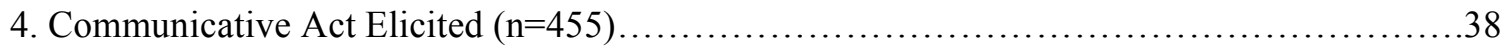

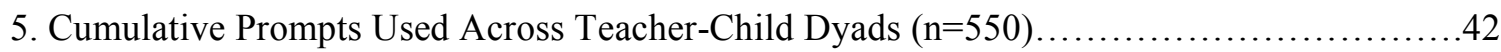

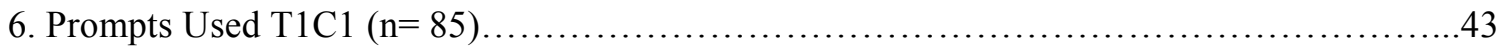

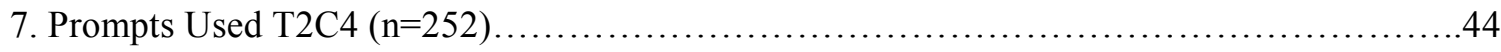

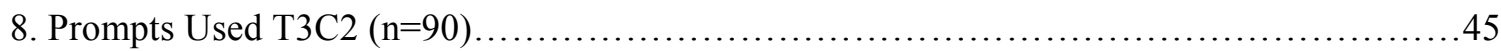

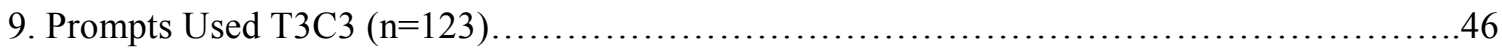

10. Comparison of Percentage of Prompt Use, All Dyads................................47

11. Least to Most Prompting Hierarchy Compared to Prompt Use...........................47 


\section{ABBREVIATIONS AND ACRONYMS AAC:}

alternative and augmentative communication SGD:

speech-generating device

CCN: complex communication needs

EI: early intervention

ALS: aided language stimulation 


\section{CHAPTER I.}

\section{INTRODUCTION}

The purpose of this thesis is to examine the prompts and cues used by teachers in dyadic interactions with their very young students learning to use alternative and augmentative communication (AAC), specifically speech-generating devices (SGDs), for communication. While children with disabilities, which often include lifelong complex communication needs, are attending preschool and using SGDs with increasing frequency, implementation studies for such communication methods are sparse, and rarer still with infants and toddlers. In an attempt to describe the nature of the teacher's role as communication partner and to analyze how specific prompts and cues may be used to elicit communicative acts from children, this thesis examined naturalistic interactions within the context of a training and implementation program and recorded and coded teacher prompts for analysis based on prompting hierarchy proposed by Light and Binger, 1998.

Augmentative and alternative communication (AAC) is a field dedicated to enhancing communication for all individuals with complex communication needs (Light \& McNaughton, 2012). For children with developmental delays and disabilities, for whom oral language often develops late and sometimes fails to emerge at all, AAC implementation has become increasingly endorsed by research in recent years (Boesch, Wendt, Subramanian \& Hsu, 2013; Millar, Light \& Schlosser, 2006; Romski et al., 2010; Sigafoos et al., 2009). The chronicity and severity of communication deficits in children with complex communication needs additionally validates AAC use, which is indicated and impactful across the lifespan.

The mobile technology revolution has made alternative and augmentative communication means available to and accepted by a wide variety of users (McNaughton \& Light, 2013). This is 
especially true of speech-generating devices (SGDs), electronic devices that that produce digitized and/or synthesized speech when activated by their user for communication (Rispoli, Franco, Van Der Meer, Lang \& Camargo, 2010). SGDs, in particular communication applications for Apple's $\mathrm{iPad}{ }^{\circledR}$, have been found to have social value to users and their peers, in addition to offering portability and affordability (McNaughton \& Light, 2013).

The first years of life represent a time of tremendous language growth and development for all children (Paul \& Norbury, 2012), and children with complex communication needs frequently require accommodations, reinforcement and alternate methods to approach developmental milestones and capitalize on language-rich learning environments such as inclusive preschools. With children attending preschool and using SGDs with increasing frequency, the teacher's role as communication partner is emphasized in the facilitation of alternative and augmentative means for their young students. However, best practice in implementation, and specifically ways in which children with CCN may be best prompted to communicate, are neither well-examined nor well-understood. Teachers and professionals who prepare and train teachers to elicit communicative acts from their young students with $\mathrm{CCN}$ are in need of explicit implementation procedures and efficacious techniques for practice.

The aim of this study was to fill a gap in the literature regarding the particular prompts and cues teachers are most likely to use while attempting to elicit communicative acts, or responses, from their very young students with CCN using SGDs. Within this inquiry, we sought to examine whether using one prompt over another could contribute to a teacher's success in eliciting child communicative acts, and how this might affect the dyadic communication interactions. Results and interpretations of this study can inform future explorations of this dynamic, and suggest ways in which teachers may scaffold their young students with CCN as they learn to communicate using alternative means. 
CHAPTER II.

LITERATURE REVIEW 


\subsection{Augmentative and Alternative Communication}

Augmentative and alternative communication (AAC) is a field dedicated to enhancing communication for all individuals with complex communication needs (Light \& McNaughton, 2012). With applications throughout the lifespan and across a variety of communication disorders, AAC is a broad and diverse field changing rapidly with the constant flow of technological advancement (McNaughton \& Light, 2013). AAC may be described as any method, device, technique or strategy used to compensate for reduced communicative competence by replacing or supplementing spoken language (Beukelman \& Mirenda, 2013; Light, 1988). It is defined by the American Speech-Language-Hearing Association (ASHA) as including “....all forms of communication (other than oral speech) that are used to express thoughts, needs, wants and ideas." (http://www.asha.org/NJC/AAC/). ASHA's Special Interest Group 12, which is dedicated to optimizing AAC accessibility and quality for all users, further defines AAC in their position paper as follows:

Augmentative and alternative communication (AAC) refers to an area of research, clinical, and educational practice. AAC involves attempts to study and when necessary compensate for temporary or permanent impairments, activity limitations, and participation restrictions of individuals with severe disorders or speech-language production and/or comprehension, including spoken and written modes of communications. $(2005, \mathrm{p} .1)$

The goal of AAC is the engagement of its users in various tasks of daily living, including communicative interactions and participation in activities of their own choosing. In this light, $\mathrm{AAC}$ is not seen as a technological cure to a communication problem, but a dynamic tool through which users may engage in and interact with their environments (Beukelman \& Mirenda, 2013). Certainly, the communicative functions of AAC methods have expanded and increased exponentially since the field's inception (Light \& McNaughton, 2012). Light (1989) synthesized research on $\mathrm{AAC}$ interactions and identified four major purposes underlying the communications of AAC users: 1) communication of wants/needs; 2) information transfer; 3) social closeness; - 
and 4) social etiquette. Theoretically, with an efficient device and appropriate training, the language capability of an AAC user is commensurate with their intellectual and developmental abilities and desire to communicate.

A large body of extant research provides strong evidence for the potential benefits of AAC across the lifespan, for individuals with both acquired and developmental conditions through modalities ranging from unaided sign systems to technologically advanced speechgenerating devices (Light \& McNaughton, 2012). A discussion of the benefits of AAC for children with complex communication needs, the focus of this inquiry, is reviewed in section 2.2.1.

The demographic characteristics of AAC users have always been diverse. AAC is indicated for any individual for whom oral language is the non-optimal form of communication, a group of individuals varied enough to include infants born with congenital conditions hindering speech and/or language development and adults for whom the ability to effectively communicate deteriorates as a consequence of disease (Beukelman \& Mirenda, 2013). At both extremes of the lifespan, medical advances are enabling people to survive and live longer lives, increasing both the number of children with chronic disabilities and the number of adults who ultimately require AAC to support communication as the result of disease and/or the aging process (Light \& McNaughton, 2012). The population of AAC users continues to grow and expand due both to social changes enabling many more people with complex communication needs to be present and productive members of society (Collier \& Self, 2010; McNaughton, Bryen, Blackstone, Williams \& Kennedy, 2010) and to the growing body of research providing evidence on the benefits of AAC for a variety of populations (Light \& McNaughton, 2012). Increase in AAC use is furthermore attributable to research revealing its efficacy with individuals previously considered ineligible, such as those with significant cognitive impairments (Romski, Sevcik, Barton-Husley 
\& Whitmore, 2015), or very young children lacking what were erroneously assumed to be prerequisite cognitive skills for AAC use (see section 2.2.1- AAC Indications for Children with Complex Communication Needs).

Broadly speaking, AAC methods may be considered in two subgroups: aided and unaided (Beukelman \& Mirenda, 2013). Unaided AAC methods entail communication methods that do not require external equipment or devices, for example signs or gestures. Unaided AAC methods (e.g. facial expression) are used subconsciously by all communicators and people with complex communication needs often develop novel and distinctive methods (e.g. gestures, body movements) through which to communicate. Such idiosyncratic compensations, however, are notable for their opacity, and development of a true symbolic communication system is paramount to the efficiency of unaided AAC methods, enhancing the user's ability to communicate across a variety of situations and with various communication partners (Sigafoos \& Drasgow, 2001).

Aided AAC involves the use of external equipment and/or auxiliary materials with communicative functions (Sigafoos \& Drasgow, 2001). Two common examples of this include exchange of pictures (which includes but is not limited to the Picture Exchange Communication System, commonly known as PECS) and the activation of a device that generates speech (Rispoli, Franco, Van Der Meer, Lang \& Camargo, 2010). While unaided AAC methods may be considered more natural, they often require motor development and planning to produce and abstract reasoning to comprehend. Aided AAC methods, in contrast, make language comprehensible across partners and contexts (Schladant, 2012). An explosion of speechgenerating technologies has occurred in recent years in conjunction with society's mobile technology revolution (McNaughton \& Light, 2013); these devices form the basis of our next topic review. 


\subsubsection{Speech-Generating Devices}

The first known mention of aided alternative and augmentative communication systems occurred in a 1960 book, detailing the development and implementation of conversation picture boards for patients with cerebral palsy (Caves, Shane \& DeRuyter, 2002). Since that time, a wide variety of both electronic and low-tech devices have been developed, studied and implemented, to varying degrees of success (Light \& McNaughton, 2012). One significant area of development in the field has been the introduction and evolution of speech-generating devices (SGDs).

A specific modality of AAC, SGDs (also referred to in the literature as voice output communication aids or VOCAs) are electronic devices that produce synthesized (computergenerated) and/or digitized (utilizing the pre-recorded speech of another person) spoken messages for the purposes of communication when activated by their user (Rispoli et al., 2010; Waddington et al., 2014). While many variations occur in terms of an SGD's size, shape, display, symbols and method of access (e.g. switches, direct select, eye tracking), a vast majority are equipped to serve a variety of communicative functions (Schlosser, 2003). The recent mobile technology revolution further enhances the capability of SGDs to meet a diversity of users' needs and has represented an evolution from esoteric and clunky dedicated devices to the dynamic, multi-functional, and eminently accessible systems available today (McNaughton \& Light, 2013).

The proliferation and ubiquity of mobile technologies, McNaughton and Light (2013) argue, has contributed to public acceptance and awareness of AAC technologies in general. In the past, AAC users often found themselves tethered to dedicated SGDs, a distinction given to those devices used exclusively for communication purposes and lacking connectivity to the internet or other practical capabilities (Kagohara et al., 2012). Today, many individuals are accessing communication applications through popular and socially valued devices, most notably Apple's iPad ${ }^{\circledR}$ (McNaughton \& Light, 2013). Kagohara and colleagues (2012) examined the impact of 
mobile technologies on AAC use and found they lack the social stigma often attributed to dedicated AAC devices. Indeed, a variety of personal accounts from individuals using mobile technologies for communication confirm the status of the $\mathrm{iPad} \AA$ as a desirable device for users and their peers. Furthermore, the iPad ${ }^{\circledR}$ and similar tablet technologies offer affordability, portability and high-quality voice output features (McNaughton \& Light, 2013).

In addition to these qualities, a growing body of research demonstrates the particular benefits of SGDs for communication within the broader purview of AAC. Rispoli et al. (2010) synthesized 35 studies involving SGDs in communication intervention and found promising evidence that SGDs improve communication for individuals with developmental disabilities. Of the studies included in their analysis, $86 \%$ demonstrated positive outcomes; rated on measures of certainty of evidence, $54 \%$ of studies were judged to be conclusive. However, the authors state that their analysis revealed a majority of the research is focused on the use of SGDs for instrumental communication skills (e.g. requesting) and a need for inquiries examining SGD use for a variety of communicative functions (e.g. social communication) remains (Rispoli et al., 2010).

In related findings, Iacono and Duncum (1995) found the use of an SGD paired with use of sign to be more effective than sign alone in eliciting both single words and 2-3 word combinations $(n=1)$, suggesting the benefit of SGDs may extend to their use in combination with other forms of communication. As undesirable behavior is a common characteristic in AAC candidates and is often attributed to frustration at lack of ability to communicate, it is also worth noting a study by Ganz, Rispoli, Mason and Hong (2014), which found preliminary evidence that SGDs have greater effects on behavior modification (for individuals with autism spectrum disorders) when compared to other AAC methods (e.g. picture-exchange.) 
Despite a considerable body of evidence suggesting the potential benefits of SGDs for users with a variety of communication disorders, young children, and especially those with complex communication needs, have not traditionally been considered appropriate candidates. Sections 2.2 and 2.2.1 focus on the particular vulnerabilities of children with CCN, and summarize the literature indicating the potential for AAC to meet their needs.

\subsection{Children with Complex Communication Needs}

With the acknowledgment that AAC in general and SGDs in particular offer benefits to users across the lifespan, we turn our attention to the population of the present inquiry: children with complex communication needs. The American Academy of Pediatrics collected data for a longitudinal study on childhood disability between the years 2001-2011and found that the prevalence of disability increased markedly during this period: $15.6 \%$ for non-institutionalized children less than 18 years of age, approximately $21 \%$ of which is attributable to an increase in diagnoses related to mental health or neurodevelopmental conditions. The authors acknowledge shifting diagnostic criteria (i.e. for autism spectrum disorders), increased social awareness and acceptance of disability, and acknowledgment of the benefits of early intervention as factors contributing to this overall increase (Houtrow, Larson, Olson, Newacheck \& Halfon, 2014). While the etiology and severity of childhood disability is greatly variable, a significant portion of children with disabilities have complex communication needs (CCN). Indeed, further analyses by Houtrow et al. (2014) revealed a 63.1\% increase in disability associated with "speech problems" in the ten years their study covered.

The children in the present inquiry represent a subgroup (infants and toddlers; or children under the age of four) for whom the disability prevalence growth rates outpace the average. 
Houtrow et al. (2014) found that children under the age of 6 had a $62.1 \%$ increase in disability diagnosis (as compared to $15.6 \%$ increase across ages $0-18$ ). Further illustrating this point, there were 336, 895 children aged birth through 35 months enrolled in Part C of the Individuals with Disabilities Education Act (IDEA) in the year 2011, the latest year for which such data are available. This enrollment rate represents $2.8 \%$ of the population receiving early intervention (EI) services, an increase from the 2002 rate of 2.2\% (National Center for Education Statistics, 2011; https://nces.ed.gov/fastfacts/display.asp?id=6).

Communication impairment, and resultant complex communication needs, may be a child's primary diagnosis or a result of genetic syndrome, injury or global developmental condition (Beukelman \& Mirenda, 2013). Children with disabilities, regardless of etiology, often have concomitant characteristics such as motoric and cognitive impairments that further hinder communication development and skills. These children often lag far behind their peers in language acquisition, and may fail to develop any oral speech (Rispoli et al., 2010). The impact of language delays and disorders can be lifelong, diverse and harrowing. Research shows that parents and other communication partners provide less language input to children diagnosed with disabilities (Paul \& Norbury, 2012). According to the National Center for Education Statistics (2013), many children with complex communication needs are still denied access to appropriate general education settings; more than $55 \%$ of children with intellectual and developmental disabilities and over $70 \%$ of children with multiple disabilities receive the majority of their instruction outside of regular education classrooms, a figure Light and McNaughton (2015) attribute, at least in part, to their limited communication skills and lack of ability to participate.

In addition to lack of access to educational opportunities, children with complex communication needs grow into adults with complex communication needs, and the impact of their communication deficits can hinder social inclusion, employability, options for independent 
living and general well-being. Less than $10 \%$ of students with $\mathrm{CCN}$ enter adulthood with functional literacy skills (Foley \& Wolter, 2010) and less than 5\% of adults with CCN are employed (McNaughton, Light \& Arnold, 2002). Worse still, 45\% of adults with CCN report being victims of abuse or crime; a staggering majority of these (97\%) report knowing their abusers but lacking the ability to effectively report or communicate these events (Bryen, Carey \& Franz, 2003; Collier, McGhie-Richmond, Odette, \& Pyne, 2006).

Given the chronicity and persistence of communication deficits, children with complex communication needs are natural candidates for AAC. Early intervention (EI), then, becomes a tool through which communication skills of children with CCN can be ameliorated and optimized to their greatest functional potential, hopefully negating some of the adverse effects of impaired communication across the lifespan. Increase in EI services in recent years is largely due to the body of research supporting the fact that the first years of life present the best opportunity to promote language acquisition, along with other developmental domains, in young children with CCN (Romski et al., 2015). In addition to the specialized preschool experiences and ancillary services these children receive (including speech-language therapy), the integration of technology in the classroom to support communication represents another opportunity to promote language growth (Barker, Akaba, Brady \& Thiemann-Borque, 2013). Alternative and augmentative communication (AAC) is one such evidenced-based practice targeting the core communication deficits of very young children with CCN (Romski, et al., 2010).

\subsubsection{Indications of AAC/SGDs for Children with CCN}

For children with typical development, a tremendous amount of speech and language acquisition occurs within the first years of life. While research has shown that the brains of 
children with disabilities and complex communication needs are likewise primed for language learning, these children frequently require alternate methods, accommodations and increased reinforcement to meet important developmental milestones (Paul \& Norbury, 2012). Due in part to their particular deficits, children (and especially infants and toddlers) with $\mathrm{CCN}$ were for many years not considered eligible for AAC based on erroneous "candidacy models" requiring prerequisite linguistic and cognitive skills (Beukelman \& Mirenda, 2013). In 2003, the National Joint Commission for the Communication Needs of Persons with Severe Disabilities (NJC) issued a position statement addressing, and refuting, AAC candidacy models. It reads, in part:

...decisions regarding... service delivery models should be based on the individual's communication needs and preferences. Eligibility determinations based on a priori criteria violate recommended practice principles by precluding consideration of individual needs. These...include but are not limited to: (a) discrepancies between cognitive and communication functioning; (b) chronological age; (c) diagnosis; (d) absence of cognitive or other skills purported to be prerequisites; (e) failure to benefit from previous communication services and supports...(NJC, 2003, p.2).

In recent years, and in large part due to NJC's statement, alternative and augmentative communication has emerged as an efficacious method for addressing the speech and language acquisition and development of children with $\mathrm{CCN}$.

It is widely documented that AAC methods, and specifically speech generating devices (SGDs) improve outcomes for children with complex communication needs (CCN) (Boesch, Wendt, Subramanian \& Hsu, 2013; Millar, Light \& Schlosser, 2006; Romski et al., 2010; Sigafoos et al., 2009). For the purpose of this review and to narrow the scope of this inquiry, we will focus on the particular indications of aided AAC methods for children with CCN. While previously considered a negative and even disqualifying factor, age is stated in some current literature as a boon to language-learning ability with AAC. (Ganz et al., 2012) note significantly better results with younger participants with autism spectrum disorders (ASD) learning to use AAC, and Ganz et al. (2014) found preschoolers with ASD had superior results in learning AAC 
methods than any other age group considered. AAC intervention with young children has been shown to impact speech and language acquisition and development, as well the social behaviors associated with effective communication (Barton, Sevcik \& Romski, 2006; Romski et al., 2015; Millar et al., 2006).

Language intervention incorporating AAC has been shown to positively impact speech and language acquisition and development. Barton et al. (2006) found that early AAC intervention resulted in an increased use of symbolic language, such as single signs and symbol vocabulary, for children aged 3 and under. Elsewhere, Romski et al. (2010) compared children receiving AAC intervention to peers who received spoken language therapy alone and found more expressive language acquisition in the subjects for whom AAC was incorporated into therapy. Indeed, the target vocabulary for the experimental group increased during the course of the research to meet their expanding communication needs (Romski et al., 2010).

Relative to the development of expressive language, it is important to specify that research suggests AAC will not impede the emergence of spoken language and may, in some cases, enhance its development (Millar et al., 2006). Numerous studies in a wide variety of populations find that AAC intervention pose no risk to either speech development or recovery, and strong evidence supports the precept that children who use AAC from a very young age can progress in their language development and eventually generate their own intelligible spoken utterances (Beukelman \& Mirenda, 2013; Romski et al., 2015; Schlosser \& Wendt, 2008).

Additionally, research demonstrates the effect of AAC interventions on the social behaviors associated with effective communication (Barton et al., 2006; Millar et al., 2006; Romski et al., 2010). Social communication is an essential component of language learning for children with $\mathrm{CCN}$ and often an area of deficit for children in this diagnostic category (Matson $\&$ Wilkins, 2007). Early AAC intervention has been found to increase communicative initiations 
(Dicarlo \& Banajee, 2000), joint attention and social reciprocity (Morgan et al., 2014). Morgan and colleagues (2014) emphasize the need for social communication AAC interventions that maximize child active engagement and address multiple outcomes, goals buoyed by the use of the technology associated with many forms of aided AAC, including but not limited to SGDs (Morgan et al., 2014). Also relative to social communication, Barker et al. (2013) present compelling evidence that including peers in AAC interventions promotes both AAC use and language outcomes.

Within the broader field of AAC, speech generating devices (SGDs) stand out as particularly effective tools for expanding a child's communicative functions beyond requesting and facilitating the development of more intentional communicative behaviors (e.g. joint engagement) and symbolic communication (e.g. symbols and words; Sigafoos et al., 2009). Furthermore, SGDs may be an appealing option for young children, who are oftentimes motivated by technology, and they provide auditory input (e.g. child hears the word after activating the device), making them an effective tool for learners benefitting from multi-modal methods (Solomon-Rice \& Soto, 2014).

In light of recent research, AAC use with very young children appears to be on the rise. Studying toddlers (chronological age 24-36 months) with communication delays, Banajee, Dicarlo and Buras Stricklin (2003) note three major factors contributing to this increase:

1. Funding: Part C of IDEA (full implementation includes funding for assistive technology for children with special needs age birth-3 years)

2. Accessibility: AAC is easier to use and costs less due to technological advances 3. Acceptance: of recommendations from AAC researchers and clinicians working with infants and toddlers, even prior to their acquisition of what were previously considered prerequisite cognitive skills 
Despite these promising developments, there is a need for additional research on the use of SGDs in children under the age of three. In a synthesis review of early AAC intervention by Romski and colleagues (2015) covering 30 years of early intervention AAC research, found that only 13 of the 143 studies (9\%) involved the use of SGDs with infants and toddlers. While emerging evidence supports AAC and SGD used in very young children with $\mathrm{CCN}$, there is a vital need both to disseminate current findings to families and professionals and for research to

further explore how speech-generating technologies can be used in developmentally appropriate ways to facilitate and promote language development in young children with $\mathrm{CCN}$. This is especially relevant given the evidence rejecting developmental and cognitive candidacy models for AAC use (Romski et al., 2015). While evidence-based best principles for developmentallyappropriate AAC early interventions are not well-defined or understood, there is a significant body of research addressing AAC implementation in general; this is our next topic of review.

\subsection{AAC Implementation}

At the inception of the field, AAC goals closely resembled generic language goals, with a focus on traditional measurements such as mean length of utterance and lexical development (Light \& McNaughton, 2012). Over time, however, research and experience led to recognition of the importance of functional communication, the ultimate measure of the degree to which an AAC user can utilize their device in order to participate in preferred activities and daily life (Beukelman \& Mirenda, 2013). Outcome measures in the field are now more focused on this holistic view, and there is increased awareness for the diversity of factors impacting communication that must be accounted for as an AAC system is implemented (Beukelman, 1991). 
Ultimately, the goal of AAC intervention is to allow an individual to learn new communication skills which will enhance their communicative competence in everyday life and allow them to experience the power of human communication (Light \& McNaughton, 2014). Communicative competence, a perhaps overlooked developmental milestone achieved by around age 3 for individuals with typical development, is defined by Light (1989) as "the ability to communicate functionally in the natural environment and to adequately meet daily communication needs." To this end, Light (1989) proposed system of competencies for the evaluation for and implementation of AAC with four components:

1) Linguistic competence refers to both receptive and expressive language skills of both the language spoken in an individual's community and the linguistic code needed for use of the individual's device (e.g. words, letters, pictures, signs).

2) Operational competence is the technical skill required for efficient and accurate AAC use (e.g. the fine motor control needed to use American Sign Language, or the ability to isolate's one's head movements in order to use a tracking system)

3) Social competence, for example the ability to initiate, maintain and appropriately terminate or change a topic of conversation, are the skills in the mores of social interaction. This would also include the ability to communicate and express a wide range of communicative functions (e.g. request, greet, protest).

4) Strategic competence refers to the compensatory strategies and individual using AAC has at disposal to repair communication breakdowns when they occur. For example, an AAC user may need to explain to new communication partners how best to interact with them. 
In an addenda to this original list of components, Light (2003) added psychosocial factors including resilience, motivation, confidence and attitude, noting their important impact on an individual's attainment of true communicative competence.

In a 2014 review of her original construct for communicative competence in AAC, Light, working with her colleague David McNaughton, determined that while the original framework proposed years earlier is still useful and relevant, the demands for competence placed on AAC users have shifted and increased with both the positive societal changes regarding individuals with disabilities and the connectivity of communication in today's world. While AAC users were often relegated to institutional setting in the past, and functional communication was chiefly faceto-face with caretakers and peers, they are now valuable and contributing members of society, communicating with a variety of people across settings and modes (e.g. email, blogging, social media) (Light \& McNaughton, 2014).

In order to address all areas of competency required for optimal AAC use, many training, teaching and learning strategies have been proposed. The literature heavily stresses the importance of involving family members to be effective communication partners who can facilitate meaningful opportunities for the AAC user to communicate, in addition to training the user in all competency areas (Beukelman \& Mirenda, 2013; McNaughton \& Light, 1989). AAC methods are not natural forms of communication for either the user or their communication partner, and Beukelman and Mirenda (2013), amongst others, note that communicative competence is built through focused and concerted interventions.

Most commonly, AAC training begins by teaching individuals to request access to highly preferred objects (Sigafoos, et al 2009). One example, and probably the best-known training protocol for AAC implementation commercially available is the Picture-Exchange Communication System (PECS; Bondy \& Frost, 2002). While designed specifically for use of 
PECS, Bondy and Frost's training procedures are based on empirically validated behavioral training strategies (e.g. response prompting, shaping, fading, differential reinforcement) that Sigafoos et al. (2009) found effective with a variety of AAC modes. However, many researchers in the field cite an over-emphasis on requesting in AAC training, and the need to identify effective methods by which to facilitate the development of most diverse language functions and more advanced language goals (Dicarlo \& Banajee, 2000; Rispoli et al., 2010). For example, Rispoli and colleagues (2010) note that no review to date has been published on the variety of communicative functions used with different types of SGDs.

Other strategies used in AAC implementation frequently cited in the literature include discrete trial training and milieu teaching. Rispoli et al. (2010) analyzed 35 studies of AAC implementation for individuals with developmental disabilities and found that requesting was the communicative function most often targeted in studies in which discrete trial training was used, and studies support its effectiveness in teaching similarly early communication behaviors. Under the discrete trial training umbrella, methods such as time-delay and least-to-most prompting may be employed. In contrast, milieu teaching and similar naturalistic approaches are more useful for teaching social communication skills such as initiation and conversational turn-taking (Rispoli et al., 2010). Enhanced milieu teaching (EMT) utilizes environmental arrangement to promote children's engagement with communication partners and in activities, interaction techniques to create conversational interactions and the opportunity to model new language forms and prompts and models that illustrate the functional use of new language forms in practice (Hancock \& Kaiser, 2002).

Ultimately, the effects of AAC implementation are mediated by the setting in which intervention is provided (Ganz et al., 2014). With young children with CCN spending increasing amounts of time in child care (United States Department of Education), such programs represent 
an opportunity for $\mathrm{AAC}$ implementation research and practice. The findings in this area are presented in our next review.

\subsubsection{AAC Implementation in Classrooms/The Teacher's Role}

From 2002 to 2011, the United States saw an increase (from 2.2\% to $2.8 \%$ of the population) in enrollment for Part $\mathrm{C}$ of the Individuals with Disabilities Education Act (IDEA), the program covering early intervention (EI) services for children with disabilities under the age of three (United States Department of Education). Amongst the increasing numbers of children receiving services and participating in early childhood experiences (such as inclusive preschool) are those with complex communication needs, often the result of developmental delays, intellectual disabilities and/or known genetic syndromes (Houtrow et al., 2014). Increase in EI services is attributable to the large body of research supporting the fact that the first years of life present the best opportunity to promote language acquisition, amongst other developmental domains (Romski et al., 2015). In addition to the specialized preschool experiences and ancillary services these children receive (including speech-language therapy), the integration of technology in classrooms to support emergent communication represents another opportunity to promote language growth (Barker et al., 2013). Alternative and augmentative communication in general, and speech-generating technologies in particular, represent an area of evidence-based practice targeting the core communication deficits of young children with CCN (Romski, et al., 2010).

Despite the fact that young children spend an increasing amount of time in child care, and that IDEA Part C requires that children's early intervention services be provided in natural environments, amongst them inclusive educational settings serving children with and without disabilities, (http://www.wrightslaw.com/info/ei.index.htm\#sthash.87oeVltA.dpuf; IDEA Part 
C34 CFR §303.12(b)) ), the majority of research on AAC implementation focuses on intervention contexts with highly specialized interventionists or explores parent dyads (Barker et al., 2013).

Teachers play an essential role in AAC early intervention because they are the key communication partners providing both language stimulation and access to important social experiences throughout a child's day (Brady, Thiemann-Borque, Fleming \& Matthews, 2013). An ideal framework through which a child may develop and practice his/her skills as an effective communicator is proffered by the context of the language-rich classroom environment, such as that which exists in inclusive preschool settings (Romski et al., 2015). Teachers play an essential role both as communication partners and as facilitators of a child's participation and engagement in classroom activities, which relates to the social aspects of communication addressed with AAC. When AAC is introduced for a young child with $\mathrm{CCN}$ in preschool, the teachers' role as gatekeeper to communication in the classroom is paramount (Barker et al., 2013).

Evidence drawn from AAC interventions implemented in general education settings suggest stronger treatment effects when compared to special education classroom, therapy room or even home settings, suggesting the potential for both academic and social inclusion (Ganz et al., 2014). The notion that communication therapy by way of AAC be implemented in inclusive classrooms is also fitting given IDEA's requirement that children with disabilities receive education in the least restrictive environment. Furthermore, the benefit of peer involvement in AAC interventions (Barker et al., 2013) lends further support to the notion of the inclusive classroom context as ideal for AAC implementation.

Douglas, Light and McNaughton (2012) explored the classroom context for implementation by training para-educators to promote turn-taking and increase the quantity of communication opportunities for young students using AAC. They found preliminary evidence 
that a 2-hour one-on-one training highlighting best practices for AAC implementation had a positive impact on communicative interactions between children and para-educators during play activities, as measured by the creation of more communicative opportunities created by the paraeducator and increase turn-taking on the child's part (Douglas, Light \& McNaughton, 2012). Communication partner instruction has also been shown to be an effective strategy for teaching educational assistants (EAs) to facilitate the communication skills of young AAC users. In a study by Binger, Kent-Walsh, Ewing and Taylor (2010), three EAs were able to help students increase their use of multi-symbol messages using speech-generating devices.

The language-rich classroom context provides many opportunities for language growth moderated with AAC, and represents an "authentic communication context" (Brady et al., 2013, p.1605 ) relevant to the communication experiences of children with $\mathrm{CCN}$, and therefore a valuable tool for the generalization of language skills acquired. However, research investigating AAC use in classrooms reveals significant barriers to implementation. Barker and colleagues (2013) found AAC systems are used infrequently (average of 4-5 times per day) by students, teachers, and peers in classroom settings. Further investigation revealed this was mainly due to competing teacher demands and lack of teacher training, both of which interfere with teachers' ability to be effective communication partners (Barker et al., 2013).

It is essential that teachers and other classroom personnel be trained on the use of strategies to become responsive and effective communication partners for their students using AAC (Shire \& Jones, 2015). With the help of their teacher, young children with CCN may use AAC to communicate, interact and participate in classroom and play environments (Light \& McNaughton, 2012). This study was designed with these needs in mind. 


\subsection{Prompting and Cueing in AAC Implementation}

A majority of the literature regarding AAC implementation, especially with children and most particularly with children under the age of three, focuses on broad principles, for example creating communicative opportunities and focusing on a natural environment and the child's preferred activities. While the extant work provides strong evidence for AAC implementation contexts and principles, the explicit procedures of intervention remain oblique and largely unexplored. This is particularly concerning for the increasing numbers of children with CCN using AAC in early intervention classrooms, where teachers report lack of training as a major challenge for implementation (Barker et al., 2013; Shire \& Jones, 2015).

One procedure endorsed by many AAC researchers (who simultaneously call for more inquiries into its benefits for AAC users) is Aided Language Stimulation (ALS), in which a communication partner directly models the use of a communication skills utilizing the user's methods (Beck, Stoner \& Dennis, 2009). For example, the communication partner teaching a young child to use an SGD would activate an icon in order to produce the device's voice output and provide natural consequences, thereby demonstrating communicative function of the device for the user. Afterwards, the communication partner should facilitate an opportunity for the AAC user to utilize the device in a similar way. While most of the demonstrated empirical benefits of ALS do not involve its use with AAC, Harris and Reichle (2004) demonstrated that ALS use with three preschool children with disabilities resulted in a slow but statistically significant increase in the children's production and comprehension of symbols.

Johnston, McDonnell, Nelson and Magnavito (2003) demonstrated intervention strategies for teaching communicative behaviors with AAC devices in the context of preschool classroom activities; they used peer and teacher models to create communicative opportunities and provide access to natural consequences of interactions (e.g. immediately providing an object/action 
requested). Kagohara, et al. (2012) demonstrated the effectiveness of physical prompting and differential reinforcement to teach two of three individuals with disabilities to request snacks and toys with a communication application for the iPad ${ }^{\circledR}$. Kent-Walsh and McNaughton (2005) reviewed 15 years of AAC instructional programs for individuals with disabilities and identified four common themes: (1) use of expectant delay (also known as extended conversational time pause); (2) responsivity to communicative attempts; (3) use of open-ended questions and (4) modeling of AAC system use (Kent-Walsh \& McNaughton, 2005).

While these studies provide some preliminary evidence for communication facilitation, the question of what to do if these attempts are unsuccessful remains. This is an important question that can inform future research direction in the field, especially given that AAC users, and especially young children who are beginning communicators, require intensive communication interventions to allow them to become effective communicators (Light \& Binger, 1998). Such intervention, especially in its early stages, will often require the communication partner (e.g. therapist, teacher, parent) to prompt the individual to respond (Gadberry, 2012).

Building on a body of research dedicated to the support of skill acquisition for students with disabilities in various domains, Light and Binger (1998) explicate an instructional procedure in depth in their book "Building Communicative Competence with Individuals Who Use Augmentative and Alternative Communication." This includes a "least-to-most" prompt hierarchy, to be used as new communication skills are targeted and practiced; Light and Binger's continuum of prompts is:

(1) natural cue- an opportunity to use the target skill that occurs during the natural course of an activity or conversation

(2) expectant delay- the opportunity to use the target skill is marked with a purposeful time-delay procedure, which may also include social communication cues on part of the 
communication partner, such as maintaining eye contact and an expectant facial expression

(3) point- a gestural prompt used in order to make it clear to the individual that they are expected to respond or communicate

(4) model- the communication partner demonstrates the target skill

The authors also suggest the use of a touch prompt, especially for users who may not benefit from a pointing cue due to limitations in visual attention or acuity (Light \& Binger, 1998) and draw on the work of Reichle and Sigafoos (1991) in suggesting that physical guidance (commonly referred to as "hand-over-hand assistance) may be necessary for AAC users who are not responding spontaneously and who do not readily imitate models. (Light \& Binger, 1998)

While Light and Binger caution that the individual should always be given the opportunity to respond or communicate spontaneously (hence the "least-to-most" structure of the prompt hierarchy), such initiations are notably rare amongst young children with $\mathrm{CCN}$ beginning to use AAC (Carter, 2003).

Given the need to design and evaluate teacher-implemented interventions including the use of speech-generating devices for young children with complex communication needs, this study adapts the above-described prompt hierarchy (Light \& Binger, 1998) to examine teachers' behaviors as communication partners and explore the relationships between prompts used and the elicitation of intentional communicative acts. 


\subsection{Summary}

Augmentative and alternative communication (AAC) provides an opportunity to support the language growth of children with complex communication needs $(\mathrm{CCN})$ who are delayed in their development of oral language (Romski, et al., 2010). As increasing numbers of children with CCN participate in early childhood educational experiences (United States Department of Education, 2011; http://tadnet.public.tadnet.org/pages/712.), the teachers' role as a communication partner is re-framed in light of the opportunity to integrate technology (e.g. speech-generating devices) in the classroom to support communication (Barker, Akaba, Brady \& Thiemann-Borque, 2013). There is a vital need for research to explore how AAC can be used in developmentally appropriate ways to facilitate language development and full participation in natural environments for young children with CCN (Romski, Sevcik, Barton-Hulsey, \& Whitmore, 2015).

Within the broader field of AAC, speech generating devices (SGDs), stand out as particularly effective tools for expanding a child's communicative functions and facilitating the development of more intentional communicative behaviors (e.g. joint engagement) and symbolic communication (e.g. symbols and words; Sigafoos et al., 2009). Furthermore, SGDs are notable for their accessibility, affordability, portability and social value (McNaughton \& Light, 2013) and may be an appealing option for young children with CCN who are often motivated by technology (Solomon-Rice \& Soto, 2014).

While early intervention classrooms represent an environment in which communication goals are targeted, under-utilization of AAC in classrooms is prevalent, appearing to be tied to both competing teacher demands and lack of teacher training, both of which interfere with teachers' ability to be effective communication partners (Barker et al., 2013). Therefore, training teachers on the use of effective strategies to support AAC use is an essential component of 
interventions to scaffold language as young children with $\mathrm{CCN}$ learn to communicate (Shire and Jones, 2015).

It is essential that individuals who use AAC are able to do so in all their communicative environments (Downing, 2005). In order to generalize their expressive language skills to all settings, AAC users, and especially young children who are beginning communicators, require intensive communicative interventions that allow them to learn effective communication skills (Light \& Binger, 1998). Such intervention, especially in its early stages, will often require the communication partner (e.g. therapist, teacher, parent) to prompt the individual to respond (Gadberry, 2012). Supporting such intentional communication, which requires joint attention and the involvement of a communication partner, is an essential component of AAC training. In order to contribute to the knowledge base for teachers and other professionals implementing AAC and SGD use with very young children in the classroom context, this study uses an established prompt hierarchy (Light \& Binger, 1998) to analyze teachers' behavior as communication partners and to explore the relationship between prompts used and the elicitation of communication acts from young children using SGDs. 
CHAPTER III. METHOD 


\subsection{Purpose}

The purpose of this study was to explore the communication interactions between teachers and their very young students with communication disorders who are learning to use augmentative and alternative devices for communication (AAC); more specifically, speech- generating devices (SGDs). In order to contribute to the knowledge base for educators and those training educators on best practices, there is a need to identify and detail which communication strategies (e.g. prompts) are most effective in eliciting communication acts from young children using SGDs. In an effort to help fill the gap between knowledge about AAC interventions and implementation of such interventions, a lag between the state of the science and the state of practice, this study seeks to improve pre-service and in-service AAC training for both educational and rehabilitation professionals.

Furthermore, while AAC technologies and users have benefitted from the proliferation of mobile technologies, there are challenges associated with the shifting technological landscape; namely, the danger of focusing solely on technology, and forgetting the importance of communication (McNaughton \& Light, 2013). This caution brings further importance to the need to research, design and implement effective AAC training procedures.

\subsection{Hypotheses}

This research seeks to answer the following questions:

1. Which prompts are teachers most likely to use in a one-on-one interactions with very young children with CCN who are new AAC users?

2. Which prompts are most likely to elicit an intentional communicative act from the child?

Hypothesis 1 . Teachers are more likely to use prompts utilizing oral language than those utilizing the SGD. 
Hypothesis 2. Prompts in which the device is involved will be more effective in eliciting a communicative act from the child.

\subsection{Participants}

Four child-teacher dyads participated in this study, with a total of 4 children and 3 teachers. All participants were recruited from an early childhood educational program in the southeastern United States. The center where all teachers and children were based provides early intervention services for children with disabilities from birth through kindergarten age in inclusive classroom settings. Each of the center's classrooms enrolls 10 children with disabilities and 5 children with typical development. Within this environment, it was requested that the instructional staff review Individual Family Service Plans and nominate potential candidates for this study based on the following inclusion criteria: 1) chronological age of 3 years, 11 months or younger; 2) evidence of being minimally-verbal, defined here as an expressive vocabulary of fewer than 10 words as quantified by the child's speech-language pathologist; and 3) fine-motor control sufficient or use of the Apple iPad ${ }^{\circledR}$ touch screen, as determined by the child's occupational therapist. From a pool of 62 children enrolled at the center, 4 met these eligibility requirements. Their parents were approached with an invitation to participate in the study and parental consent was obtained, as well as consent from each child's teacher. A copy of the Institutional Review Board approval for this study, as well as the Informed Consent forms for both children and teachers, are found in Appendices B-D. In total, four children and three teachers participated in the study. Child information was obtained from parent and teacher reports including the Achenbach Child Behavior Checklist (CBCL; Achenbach \& Rescorla, 2000) and Communication Matrix and Child Communication Skills Questionnaire and Child Communication and Symbolic Communication (Rowland, 2009); demographic information for each child is summarized in Table 1. 


\section{Child 1}

Child 1, a white, non-Hispanic male, was 26 months old at the start of the study. He came from a middle class family, and his mother's highest level of education attained was a Bachelor's degree. Child 1 had a diagnosis of Fragile X syndrome and demonstrated low levels of intentionality and initiation in communication. His primary modes of communication included pre-intentional behaviors such as facial expressions body movements including some unconventional gestures (e.g. raising arms). His vocalizations were limited and primarily limited to non-transcribable utterances such as squeals, guttural sounds and blowing air through his lips ("raspberries"). He was noted to spontaneously produce the open syllables "da" and "ma", as well as one example of reduplicated babbling ("vava") during an initial informal evaluation. He was able to produce an approximation of the sign for "more" when prompted. Child 1's vision and hearing were reported to be within normal limits.

\section{Child 2}

Child 2, a male of Indian (non-Hispanic) descent, was 37 months at the start of the study.

Diagnosed with seizure disorder and developmental delay, his hearing and vision were reported to be within normal limits. Informal pre-intervention assessment revealed that Child 2 had a minimal number of words (and word approximations) in his expressive vocabulary (e.g. "pop", "ba"/ball) and used the sign for "please" when prompted. His primary vocal output consisted of reduplicated babbling (e.g. vowel-consonant combinations i.e. "bababa"), and he was noted to coordinate eye contact with vocalizations, smiles and reaching to request objects. At the onset of the study, Child 2 was using primarily non-verbal means for functional communication. Child 2's family was upper middle class, with his mother's highest level of education a medical degree.

\section{Child 3}

Child 3, a white Hispanic male, was 38 months at the start of the study. His diagnoses were developmental delay and speech and language impairment. Baseline assessment's revealed no 
sounds or words used for communication. Child 3 communicated solely through pre-intentional means (e.g. pushing people away, reaching for objects). Parent reported being able to "read" their child's behavior. Child 3 demonstrated minimal social interaction and joint attention. While he did seek comfort from familiar figures, he rarely related to unfamiliar people. Child 3's hearing and vision were reported to be within normal limits. He came from a middle class family; his mother's highest degree was reported as high school diploma.

\section{Child 4}

At the start of the study, Child 4 was 19 months old. A multi-racial Hispanic male diagnosed with Down syndrome, his hearing and vision were reported to be within normal limits. Child 4 came from a middle class family, with his mother's highest degree reported to be a Master's. Child 4 used/approximated the sign for "more" with prompting, and vocalized a limited range of canonical babbling (e.g. "ma", "ba", "da"). While he consistently responded to his name and demonstrated good social awareness, Child 4's functional play was very limited, in part due to motor delays. While he enjoyed and participated in social routines such as songs, he was not yet able to walk and explore his environment, and demonstrated difficulty isolating finger movements, which affected his ability to activate the speech-generating device.

Table 1. Child Demographic Characteristics

\begin{tabular}{|c|c|c|c|c|c|c|}
\hline Child & Gender & $\begin{array}{l}\text { Age } \\
\text { (in } \\
\text { months) }\end{array}$ & Diagnosis & Race/Ethnicity & $\begin{array}{c}\text { Mother's } \\
\text { highest } \\
\text { degree }\end{array}$ & $\begin{array}{l}\text { Family } \\
\text { SES }\end{array}$ \\
\hline 1 & Male & 26 & $\begin{array}{l}\text { Fragile X } \\
\text { syndrome }\end{array}$ & $\begin{array}{l}\text { White/Non- } \\
\text { Hispanic }\end{array}$ & $\begin{array}{l}\text { Bachelor's } \\
\text { degree }\end{array}$ & $\begin{array}{l}\text { Middle } \\
\text { class }\end{array}$ \\
\hline 2 & Male & 37 & $\begin{array}{l}\text { Seizure } \\
\text { disorder; } \\
\text { Developmental } \\
\text { delay }\end{array}$ & $\begin{array}{l}\text { Indian/Non- } \\
\text { Hispanic }\end{array}$ & $\begin{array}{l}\text { Medical } \\
\text { degree }\end{array}$ & $\begin{array}{l}\text { Middle- } \\
\text { upper } \\
\text { class }\end{array}$ \\
\hline 3 & Male & 38 & $\begin{array}{l}\text { Developmental } \\
\text { delay }\end{array}$ & White/Hispanic & $\begin{array}{l}\text { High } \\
\text { school } \\
\text { diploma }\end{array}$ & $\begin{array}{l}\text { Middle } \\
\text { class }\end{array}$ \\
\hline 4 & Male & 19 & $\begin{array}{l}\text { Down } \\
\text { syndrome }\end{array}$ & Multiracial/Hispanic & $\begin{array}{l}\text { Master's } \\
\text { degree }\end{array}$ & $\begin{array}{l}\text { Middle } \\
\text { class }\end{array}$ \\
\hline
\end{tabular}


Teachers

Three teachers participated in the study, all of whom were employees of a universitybased early intervention program and had bachelor's degrees in early childhood education and a minimum of five years of experience working with children with developmental disabilities. The teachers in the study, like the children, were culturally diverse; one is African-American/NonHispanic, while the other two are White/Hispanic.

\subsection{Stimuli/Apparatus}

In preparation for the study, teachers were provided with individualized instructional support from two of the authors, an assistive technology specialist and a clinical psychologist. Initially, the teachers received a group training session consisting of a 2-hour interactive workshop covering the core components of the intervention and general principles of AAC and SGD use. Referred to as "iCanChat", this hybrid approach to AAC intervention designed by Schladant, Dowling, Coron, Nevares and Toro (2014) is based on four evidence-based strategies:

(1) focus on the child's preferences and interests (Rogers \& Dawson, 2010)

(2) participation in everyday activities (e.g. mealtime, playtime)

(3) naturalistic language strategies based on Enhanced Milieu Training (Hancock \& Kaiser, 2002) and

(4) alternative and augmentative communication tools including guided access, visual supports, core vocabulary and a communication application for $\mathrm{iPad} \AA$ based on the linguistic model of language development (Banajee et al., 2003; Sigafoos et al., 2009). The first generation of Apple iPad ${ }^{\circledR}$, equipped with the Touch Chat communication application customized using Pixons, a visual set based on multi-meaning symbols, and Language Acquisition through Motor Planning (LAMP) principles, which focus on building independent 
communication on SGDs by maximizing motor learning principles (Center for AAC \& Autism, 2009). All iPads ${ }^{\circledR}$ used were placed in protective cases with iAdapter speakers to enhance voice output. The core components of iCanChat are summarized in Figure 1.

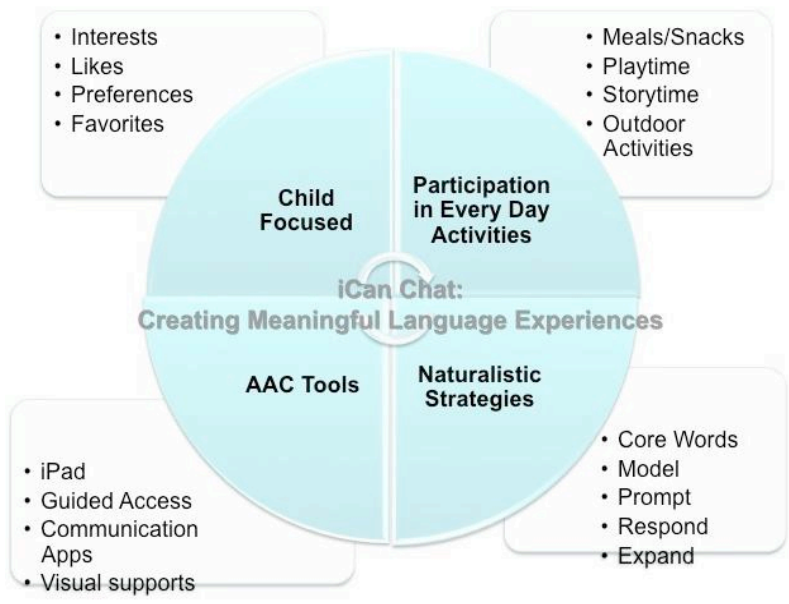

Figure 1. Core Components of iCanChat (Schladant et al., 2014).

\subsection{Design}

This study examines the relationship between two independent variables, prompt category and device use in prompting and their dependent variable: the elicitation of an intentional communicative act from the child utilizing the SGD. Operational definitions for each of these variables follow.

\section{Prompt Category (Hierarchy of prompt)}

Based on the ordinal scale presented by Light and Binger (1998) for AAC implementation, the following prompt hierarchy was designed for use in this study: 
Category 1- expectant delay may be defined as a time-delay procedure in which the opportunity to use the target skill is marked; often includes social communication cues on part of the communication partner (e.g. maintaining eye contact, leaning in)

Category 2- direct attention is any attempt on the communication partner's part that goes beyond time delay in an attempt to elicit a response from the AAC user; these strategies include:

$2 \mathrm{~g}$ - gestural cue (e.g. pointing, nodding head)

$2 \mathrm{v}$ - vocal prompt (e.g. "what do you want" or calling child's attention with a vocalization)

2t- tactile prompt (e.g. touching child's hand to call his attention to the interaction)

While this scale is ordinal in nature, there is nothing in the literature to suggest that one level of directing attention is more impactful than others. For this reason, vocal, gestural and tactile prompts are considered here as subcategories of prompt level 2.

Category 3- Model, defined as a demonstration of the target skills by the communication partner. For example, the teacher may say, "You want more" while activating the icon for "more" on the child's SGD.

Category 4- Full physical guidance; also known as "hand-over-hand" assistance, this occurs when the teacher physically guides the child to activate the device, for example by holding his hand and extending his finger in order to activate the correct icon.

See Appendix A for an example of the protocol used for data collection and coding. 
In following with the research of Carter (2003), only communicative acts in which the child fully participated could be coded as intentional. Therefore, prompt category number 4- full physical guidance disallowed the use of intentional communication, and was always coded for no child communicative act elicited. The occurrence of this prompt category was included in portions of the analysis for descriptive purposes, but excluded from others in which its static nature could confound results.

Communicative act

Defined here in following with Rowland and Schweigert (2003) as behavior that is “purposefully directed toward another person with intended meaning...[and that] requires dual orientation - orientation to both the communication partner and the topic or referent." Coding for whether or not a teacher's prompt elicited a child communicative act was done only in the affirmative or negative - a communicative act was either elicited or it was not.

Device use

Likewise, coding for device use was performed in the affirmative or negative only. If the teacher utilized the SGD in her prompting (e.g. pointing to it in an effort elicit child communication, modeling a communicative act using the device), then device use was coded. When the device was not referenced or used in anyway (e.g. the teacher tells the child, "What do you want?" without pointing or motioning towards the device), such moments were coded for no device use.

\subsection{Procedure}

For 14 weeks, teachers participated in classroom/play sessions with children using their SGD. A child interest inventory was used to select play materials and activities for these sessions, which were approximately 15 minutes at length and concluded at a natural break in play. All sessions took place in the child's classroom. Researchers were able to provide feedback to 
teachers during these sessions based on child behaviors and response, and instructional procedures for how to implement the SGD were reviewed. All videos coded for the present inquiry are taken from these sessions. At the end of the experimental period, parents of all children were given the opportunity to receive instructional support for SGD implementation and home carryover; families were allowed to keep the $\mathrm{iPad} \AA$ and communication application as incentive for their participation in this research.

A total of 109 minutes and 18 seconds of interaction recorded over 14 weeks was coded for prompt category, device use and elicitation of child communicative act. Child 1's recordings totaled 22 minutes and 56 seconds, Child 2 has 22 minutes and 53 seconds of recordings, Child 3 21 minutes, 38 seconds and Child 441 minutes and 51 seconds.

When coding was complete, the data was analyzed both to examine the relationship between the use of certain prompts and the elicitation of intentional communicative acts from children, and device use and elicitation of communicative acts. In addition, a mixed measurements approach utilizing descriptive statistics was used to further explore the data set and describe teacher behaviors as the communication partners for young AAC users. Results are found in chapter four. 


\section{CHAPTER IV.}

\section{RESULTS}

Overall, a total of 455 prompts were identified and coded across teacher-child dyads from 109 minutes and 18 seconds of recorded interaction. Table 2 illustrates the recorded and coded minutes per teacher-child dyad.

Table 2. Minutes Coded per Teacher-Child Dyad

\begin{tabular}{|l|l|}
\hline Teacher-Child & Minutes Coded \\
\hline T1C1 & 22 minutes, 56 seconds \\
\hline T3C2 & 22 minutes, 53 seconds \\
\hline T3C3 & 21 minutes, 38 seconds \\
\hline T2C4 & 41 minutes, 51 seconds \\
\hline
\end{tabular}

The prompt total $(n=455)$ reflects the exclusion of prompt category 4 (physical assistance) from the analysis, a measure taken because its use precludes the elicitation of an intentional communicative act and inclusion would confound overall results. The most frequently coded prompt was category 2 : direct attention $(n=411 ; 90.3 \%$ of the total), followed by category 3: model $(n=34 ; 7.5 \%$ of the total) and category 1 : expectant delay $(n=10 ; 2.2 \%$ of the total). Data regarding prompt use is illustrated in Figure 2. In terms of device use, the speech-generating device (SGD) was used by the teacher in 291(64\%) of prompts and not used in $164(36 \%)$. There were a total of 269 prompts (59.1\%) that elicited a communicative act from the child, and 186 prompts (40.9\%) that did not. These data are illustrated in Figures 3 and 4, respectively. 


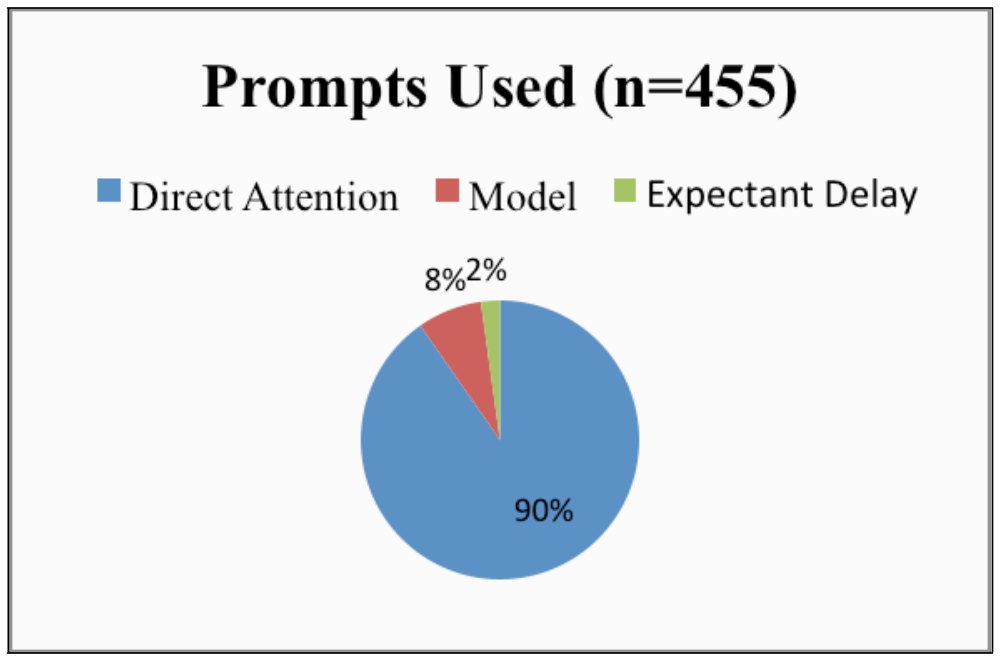

Figure 2. Prompts Used $(\mathrm{n}=455)$

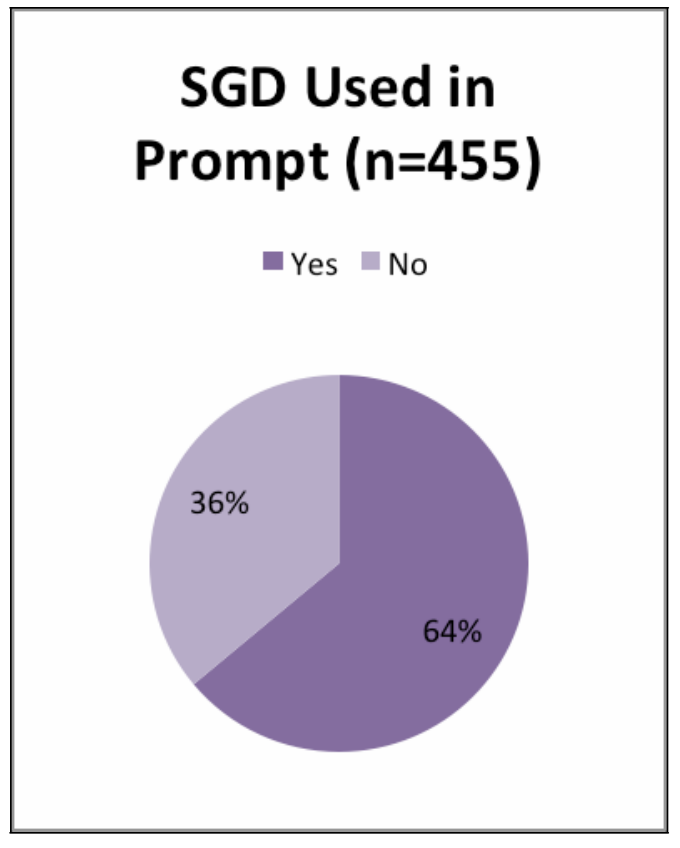

Figure 3. SGD Used in Prompt $(n=455)$

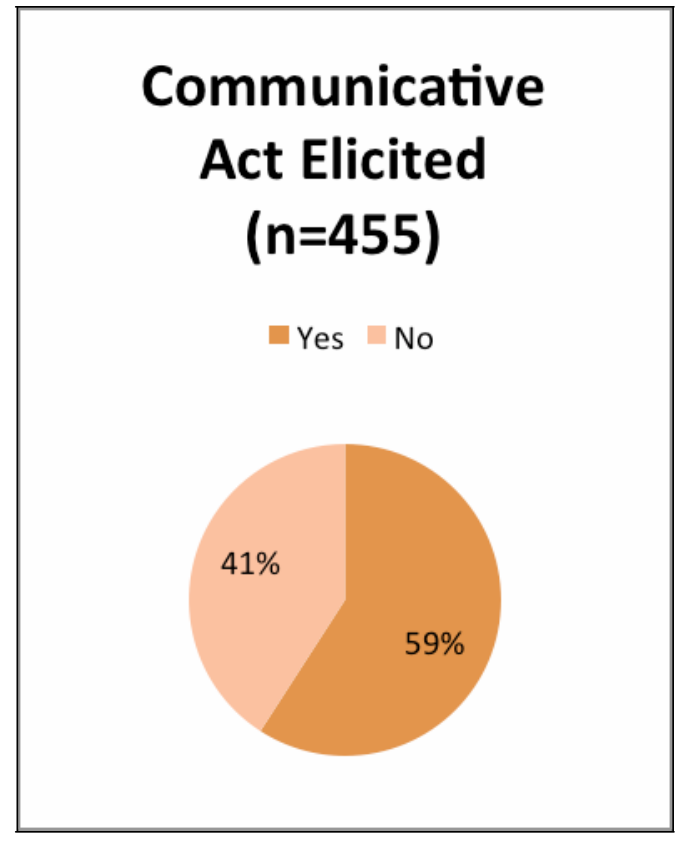

Figure 4. Communicative Act Elicited $(n=455)$ 
Test 1: Prompts and elicitation of communication acts

A chi-square test of independence was conducted to examine the difference between specific prompts utilized in eliciting communicative acts. The difference between these values was not significant, $\mathrm{X}^{2}(2, \mathrm{~N}=455) ; \mathrm{p}=0.443$. Prompt category use had no effect on the elicitation of communicative acts from children. A chi-square table for test 1 is pictured in Table 3.table

Table 3. Chi-square table for Test 1- Prompts and the elicitation of communication acts

\begin{tabular}{|c|c|c|c|c|c|}
\hline Category & Observed & Expected & $\begin{array}{c}\text { Residual= } \\
\text { Observed- } \\
\text { Expected) }\end{array}$ & $\begin{array}{c}\text { (Observed- } \\
\text { Expected) } 2\end{array}$ & $\begin{array}{c}\text { Component } \\
\text { (Observed- } \\
\text { Expected) } 2 / \text { Expected }\end{array}$ \\
\hline $\begin{array}{c}\text { ED- No } \\
\text { Response }\end{array}$ & 5 & 5.9 & -.9 & .81 & .1373 \\
\hline ED- Response & 5 & 4.1 & 0.9 & .81 & .1976 \\
\hline $\begin{array}{c}\text { DA- No } \\
\text { Response }\end{array}$ & 243 & 243 & 0 & 0 & 0 \\
\hline DA- Response & 168 & 168 & 0 & 0 & 0 \\
\hline $\begin{array}{c}\text { M- No } \\
\text { Response }\end{array}$ & 21 & 20.1 & .9 & .81 & .0403 \\
\hline M- Response & 13 & 13.9 & -.9 & .81 & .0583 \\
\hline
\end{tabular}

$\mathrm{ED}=$ expectant delay; $\mathrm{DA}=$ direct attention; $\mathrm{M}=$ model

Test 2: Device use and elicitation of communicative acts

In terms of device use, there were 291 prompts in which the device was utilized, representing $64 \%$ of the total. In $58.4 \%$ (170) of prompts in which the device was utilized, the child did not respond with an intentional communicative act; in $41.6 \%(121)$ of these cases, a communicative act was elicited. From the total of 164 prompts in which the device was not used $(36 \%)$, there was a $39.6 \%(65 / 164)$ response rate; in $60.4 \%(99 / 164)$ of cases when the device was utilized in the prompt, the child did not respond with an intentional communicative act. A chi-square test of independence was performed to examine the relation between device use and the elicitation of communicative acts. The difference between these values was not significant, $\mathrm{X}^{2}$ 
$(1, N=455) ; p=0.164$. Device use had no effect on the elicitation of communicative acts from children. A chi-square table for test 2 is pictured in Table 4.

Table 4. Device use and elicitation of communicative acts

\begin{tabular}{|c|c|c|c|c|c|}
\hline Category & Observed & Expected & $\begin{array}{c}\text { Residual= } \\
\text { (Observed- } \\
\text { Expected) }\end{array}$ & $\begin{array}{c}\text { (Observed- } \\
\text { Expected) } 2\end{array}$ & $\begin{array}{c}\text { Component } \\
\text { (Observed- } \\
\text { Expected) } 2 / \text { Expected }\end{array}$ \\
\hline $\begin{array}{c}\text { No Device- } \\
\text { No Response }\end{array}$ & 99 & 97 & 2 & 4 & .0412 \\
\hline $\begin{array}{c}\text { No Device- } \\
\text { Response }\end{array}$ & 65 & 67 & -2 & 4 & .0597 \\
\hline $\begin{array}{c}\text { Device Used- } \\
\text { No Response }\end{array}$ & 170 & 172 & -2 & 4 & .0233 \\
\hline $\begin{array}{c}\text { Device Used- } \\
\text { Response }\end{array}$ & 121 & 119 & 2 & 4 & .0336 \\
\hline
\end{tabular}

Descriptive Results

To address the question of which prompts teachers were most likely to use, descriptive summary statistics were used to analyze the behavior of each teacher and the prompts used within each teacher's sessions and cumulatively across sessions and teachers. It should be noted that the sum of totals for specific prompts used exceeds the total prompts per teacher; this is explained by the fact that teachers often (cumulative percentage $64.73 \%$ across teacher-child dyads) utilized more than 1 prompt at a time. When they did so, both prompts used were identified and coded for this descriptive portion of the analysis. Additionally, it should be noted that the cumulative total prompts across teachers $(n=550)$ exceeds the 455 prompts analyzed in the chi-square analysis above (Tests 1 and 2). This is because the use of prompt category 4 (full physical guidance) is included here for descriptive purposes, but was disregarded for the main analysis, as its use precludes the elicitation of an intentional communicative act.

In addition, due to the overwhelming prevalence of category 2 (direct attention) prompts used ( $90.3 \%$ of the total in the original analysis), a sub-analysis of this category is included in the 
descriptive analysis. In order to better understand the methods by which teachers directed child attention, this sub-analysis distributes methods of directing attention into three categories: $2 \mathrm{~g}$ : gestural, 2t: tactile and 2v: vocal.

Overall, a total of 550 prompts were identified and coded in the 109 minutes and 18 seconds of recorded interaction. Across teachers and children, the most frequently used prompt was category $2 \mathrm{v}$ (vocal prompt; $n=436 ; 79.27 \%$ ), followed by category $2 \mathrm{~g}$ (gestural prompt; $n=207 ; 37.64 \%$ ), category 3 (model; $n=151 ; 27.45 \%$ ), category 4 (physical guidance; $n=96$; $17.45 \%$ ), category $2 \mathrm{t}$ (tactile prompt; $n=21 ; 3.82 \%$ ) and lastly category 1 (expectant delay; $n=16$; 2.91\%). Within the sub-analysis of Category 2, for 664 instances in which a prompt occurred, 436 of these included $2 \mathrm{v}$ - verbal prompt (65.55\%). The device was used in a total of 385 prompts, representing $70 \%$ of all opportunities. A communicative act was elicited following 184 prompts, representing a response rate of $33.45 \%$ (no response $66.55 \%$ of the time [366/550]). However, this last figure should be interpreted with caution, as this descriptive analysis includes prompt category 4 (physical assistance) which cannot, by definition, result in an intentional communicative act by the child. The cumulative totals for each category of prompt use are illustrated in Figure 5. 


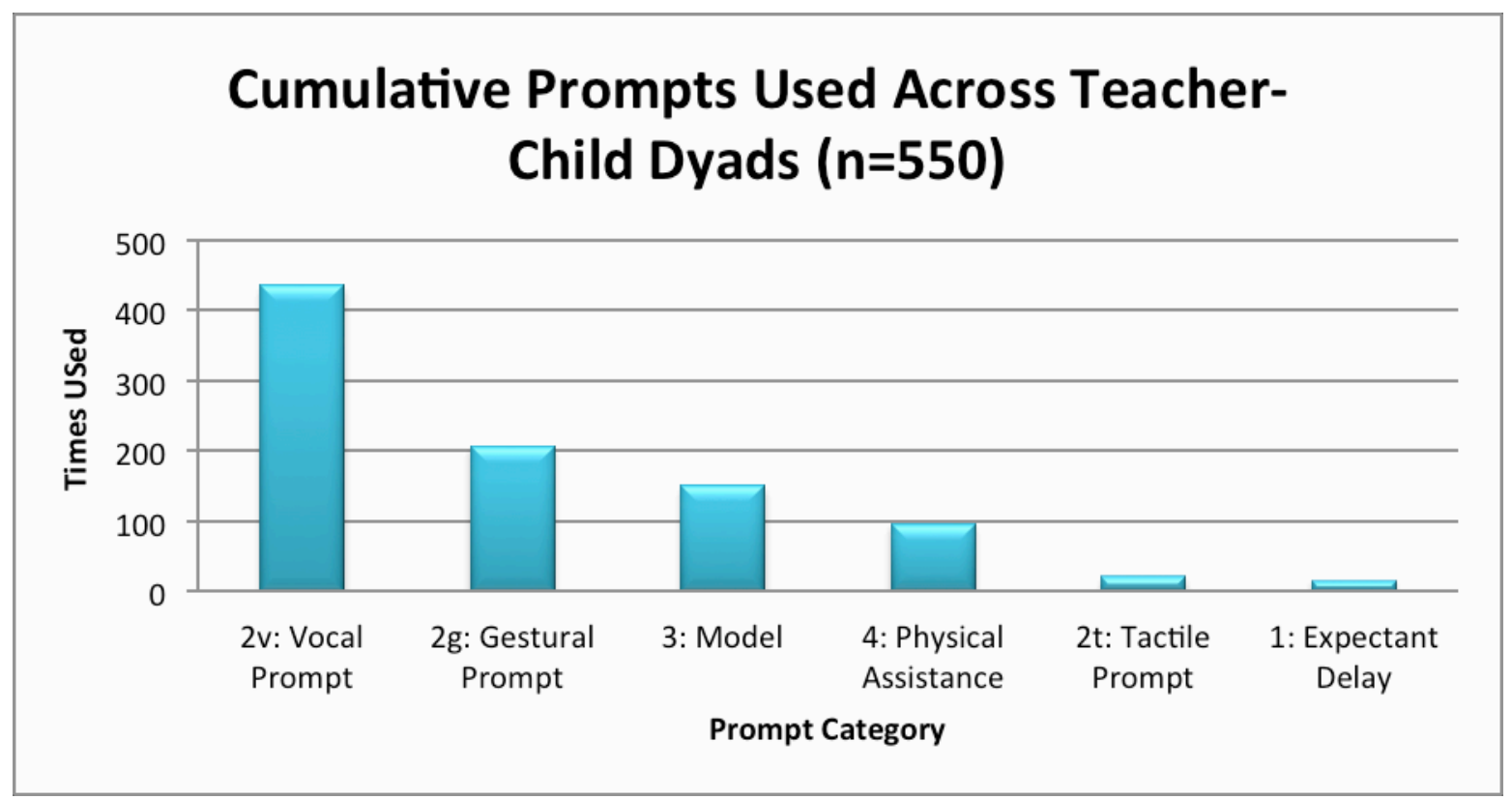

Figure 5. Cumulative Prompts Used Across Teacher-Child Dyads $(\mathrm{n}=550)$

Teacher 1

Teacher 1 had 22 minutes and 56 seconds of recorded interaction with Child 1, during which 85 total instances of prompting (utilizing 1 or prompt at a time) were recorded. Of the 85 prompting instances, 63 (74.12\%) included vocal prompts (category $2 \mathrm{v}), 19(22.35 \%)$ included gestural prompts (category 2g), 48 (56.47\%) included modeling (category 3 ) and 7 (8.24\%) included physical assistance (prompt category 4). Teacher 1 demonstrated no use of the expectant delay strategy (category 1 prompt) or tactile prompting (category $2 \mathrm{t}$ ). Teacher 1 utilized the device 64 of her 85 prompts, totaling $75.29 \%$ of the time. Child 1, working with Teacher 1 , responded to her prompting with an intentional communicative act in 45 of 85 attempts, a total of $52.94 \%$ of the time (no response in 40 of 85 opportunities, or $47.06 \%$ of the time). Figure 6 illustrates the prompts used by teacher 1 , with child 1 . 


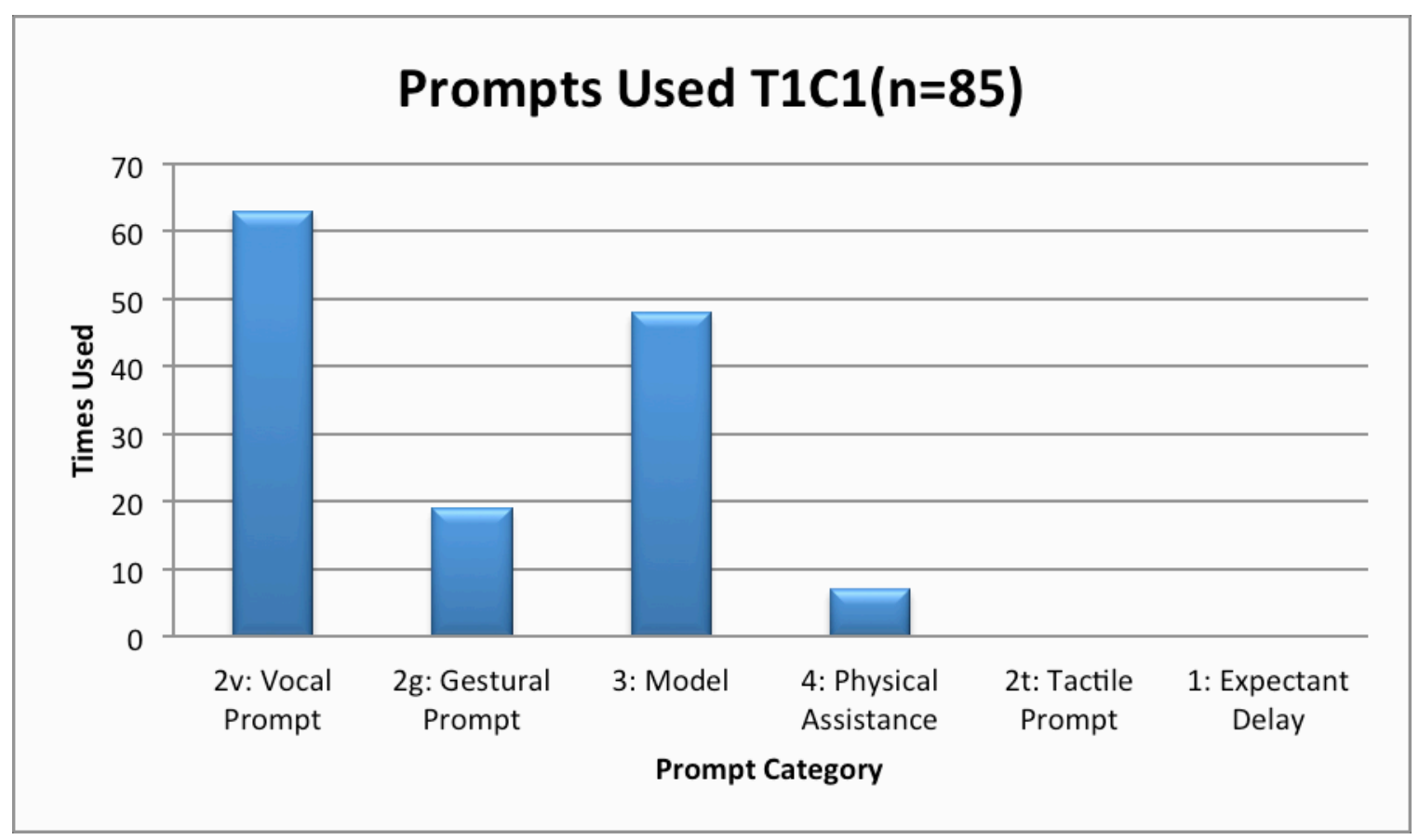

Figure 6. Prompts Used T1C1(n=85)

Teacher 2, Child 4

For Teacher 2, 41 minutes and 51 seconds of interaction with Child 4 were recorded, during which she used 252 prompts total. Of the 252 prompts, 8 (3.17\%) included expectant delay (prompt category 1), 188 (74.6\%) included vocal prompting (prompt category $2 \mathrm{v}), 6(2.38 \%)$ with tactile prompts (category $2 \mathrm{t}), 67$ (26.59\%) with gestural prompts (category $2 \mathrm{~g}), 45(17.86 \%)$ with modeling (prompt category 3$)$ and $84(33.33 \%)$ with physical assistance. Teacher 2 used the device in 167 of her prompts, representing a $66.27 \%$ device use rate. In a total of $10.71 \%$ of prompts (27 out of 252), a communicative act was elicited from Child 4, who was working with Teacher 2. Child 4 did not respond in 225 of 252 opportunities, or $89.29 \%$ of the time. Figure 7 illustrates the prompts used by teacher 2 with child 4 . 


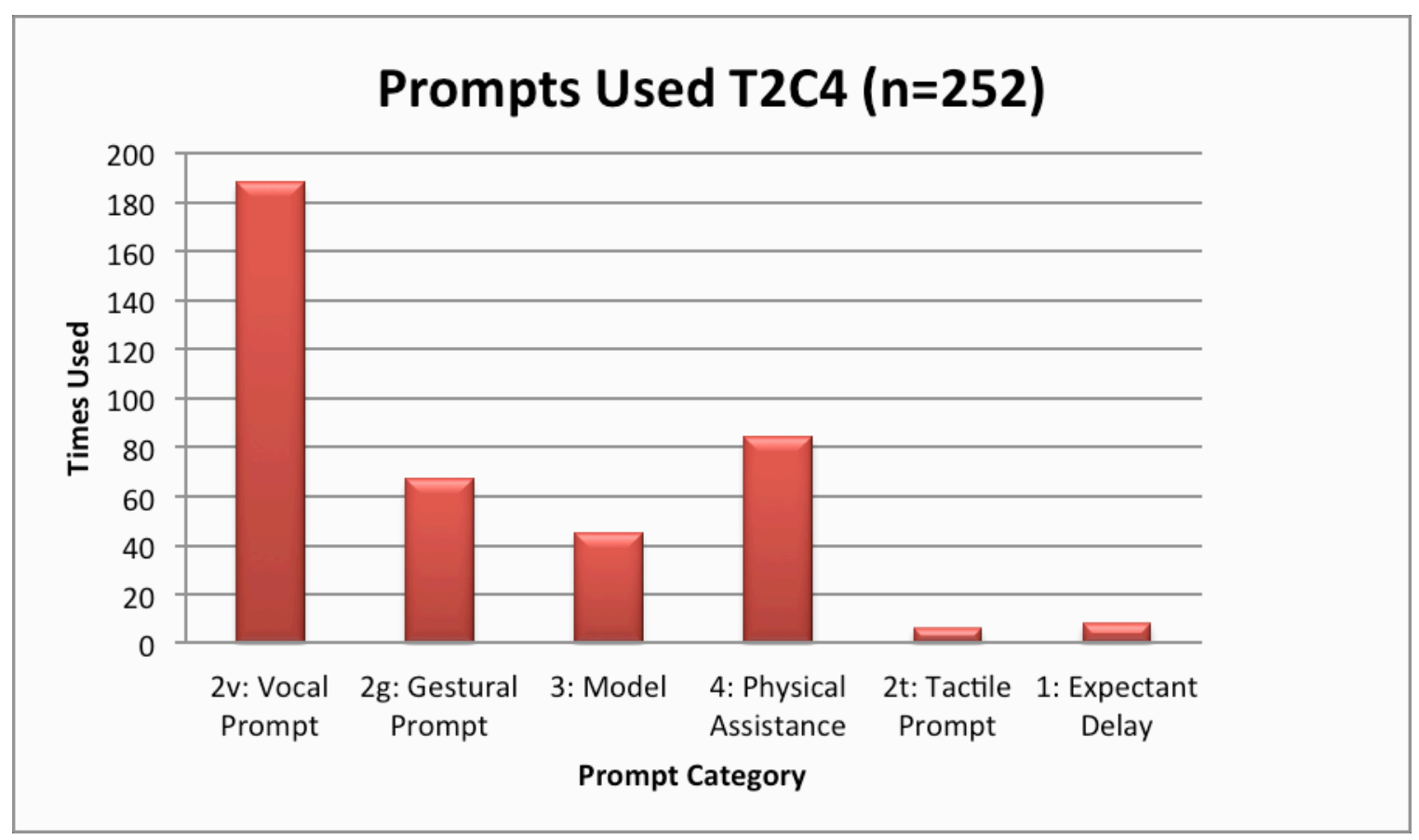

Figure 7. Prompts Used T2C4 (n=252)

Teacher 3, Child 2

Teacher 3 worked with both Child 2 and Child 3. In her interactions with Child 2, there are 22 minutes and 53 seconds of recorded interaction, and 90 recorded prompts. Of Teacher 3's prompts with Child 2, 1/90 (1.11\%) included expectant delay (prompt category 1), 86 (95.56\%) included vocal prompts (category $2 \mathrm{v}), 1$ (1.11\%) tactile prompting (category $2 \mathrm{t}), 56(62.22 \%)$ gestural prompting (category $2 \mathrm{~g}$ ), 32 (35.56\%) modeling (prompt category 3 ), and no instances of physical assistance. In these interactions, Teacher 3 used the device in $72.22 \%$ of her prompting (65 out of 90 opportunities) and intentional communicative acts were elicited from Child 2 on $81.11 \%$ of prompts (73/90 opportunities). Child 2 did not respond in $18.88 \%$ of opportunities (17/90). Figure 8 illustrates the prompts used by teacher 3, with Child 2. 


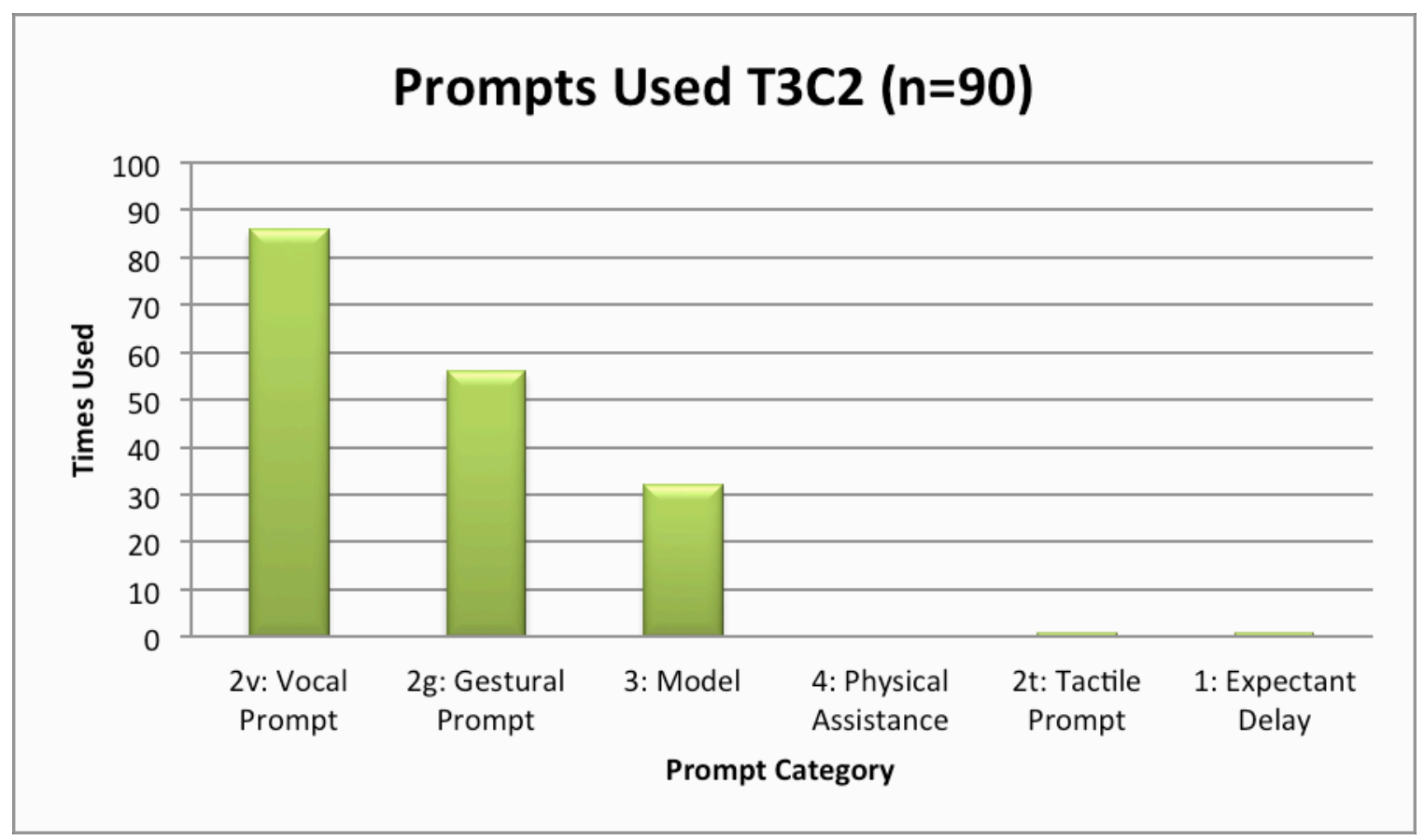

Figure 8. Prompts Used T3C2 (n=90)

Teacher 3, Child 3

Working with Child 3, Teacher 3 has 21 minutes and 38 seconds of recorded interaction and uses a total of 123 prompts. 5.69\% of her prompts (7/123) included expectant delay (prompt category 1), 80.49\% (99/123) include vocal prompts (category $2 \mathrm{v}), 11.38 \%(14 / 123)$ tactile prompts (category 2t), 52.85\% (65/123) gestural prompts (category $2 \mathrm{~g}), 21.14 \%(26 / 123)$ modeling (prompt category 3$)$ and 4.07\% (5/123) physical assistance. Across prompts, Teacher 3 employed the SGD in $72.36 \%$ of opportunities (89/123) and communicative acts were elicited from Child 3 in 31.71\% (39/123) of the prompts given. No response for Child 3 was recorded in $68.29 \%$ of opportunities (84/123). Figure 9 illustrates the prompts used by teacher 3 , with child 3 . 


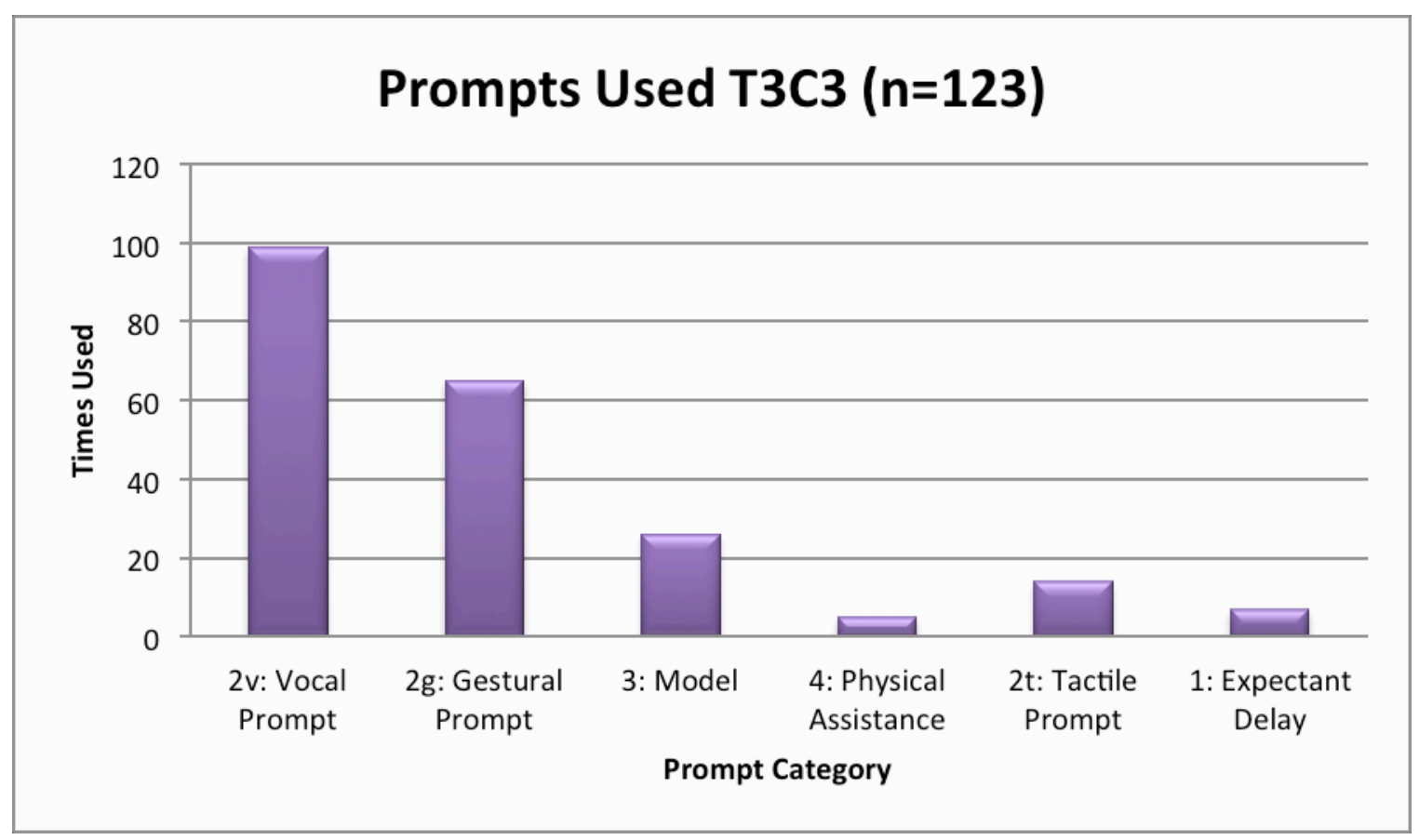

Figure 9. Prompts Used T3C3 $(\mathrm{n}=123)$

Taken as a cumulative data set, the difference between performance, defined as range of prompt use, device use and elicitation of communicative acts, varies amongst descriptive categories. Prompt category $2 \mathrm{v}$ (vocal prompt) was used in an average of $79.27 \%$ of prompts across dyads, with a range of $74.12 \%$ to $95.56 \%$. Prompt category $2 \mathrm{~g}$ (gestural prompt) was used in an average of $37.64 \%$ of prompts (range $=22.35 \%$ to $62.22 \%$ ). Prompt category 3 (model) was used in an average of $27.45 \%$ of prompts (range $=17.86 \%$ to $56.47 \%$ ). Prompt category 4 (full physical assistance was used in an average of $17.45 \%$ of prompts (range $0 \%$ to $33.33 \%$ ). Prompt category $2 \mathrm{t}$ (tactile prompt) was used in an average of $3.82 \%$ of prompts (range $=0 \%$ to $11.38 \%$ ) and prompt category 1 (expectant delay) was used in an average of $2.91 \%$ of prompts, with a range of use from $0 \%$ to $5.69 \%$. On average across dyads, the SGD was employed in $70 \%$ of all prompts (range $66.27 \%$ to $75.29 \%$ ). The range of communicative acts elicited was $10.71 \%$ to $81.11 \%$. Figure 10 compares the percentage of prompts used by individual teacher-child dyads, as well as illustrating the prompts used across dyads (for the cumulative data set). Figure 11 contains the same data presented as a function of the least to most prompt hierarchy. 


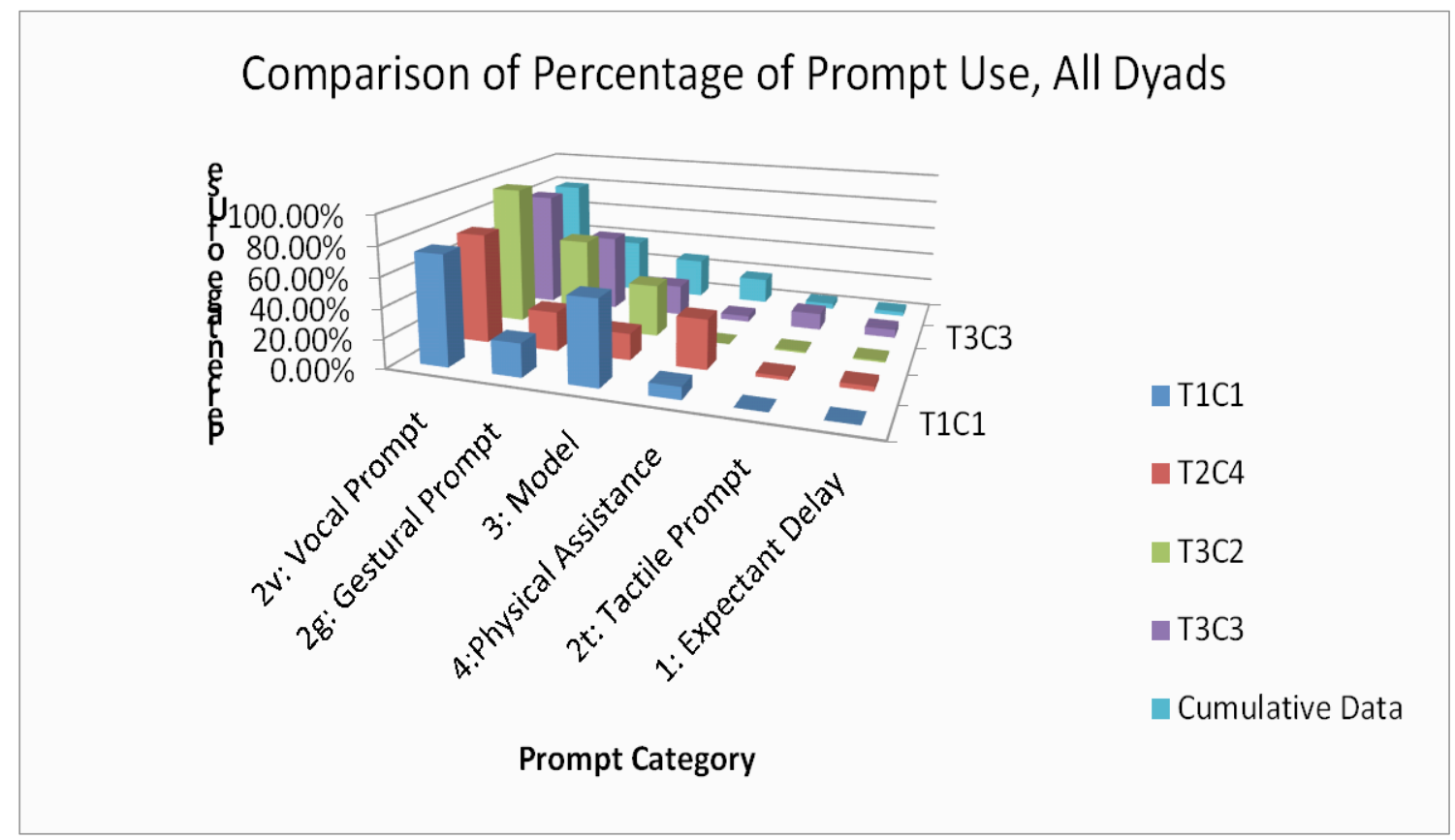

Figure 10. Comparison of Percentage of Prompt Use, All Dyads

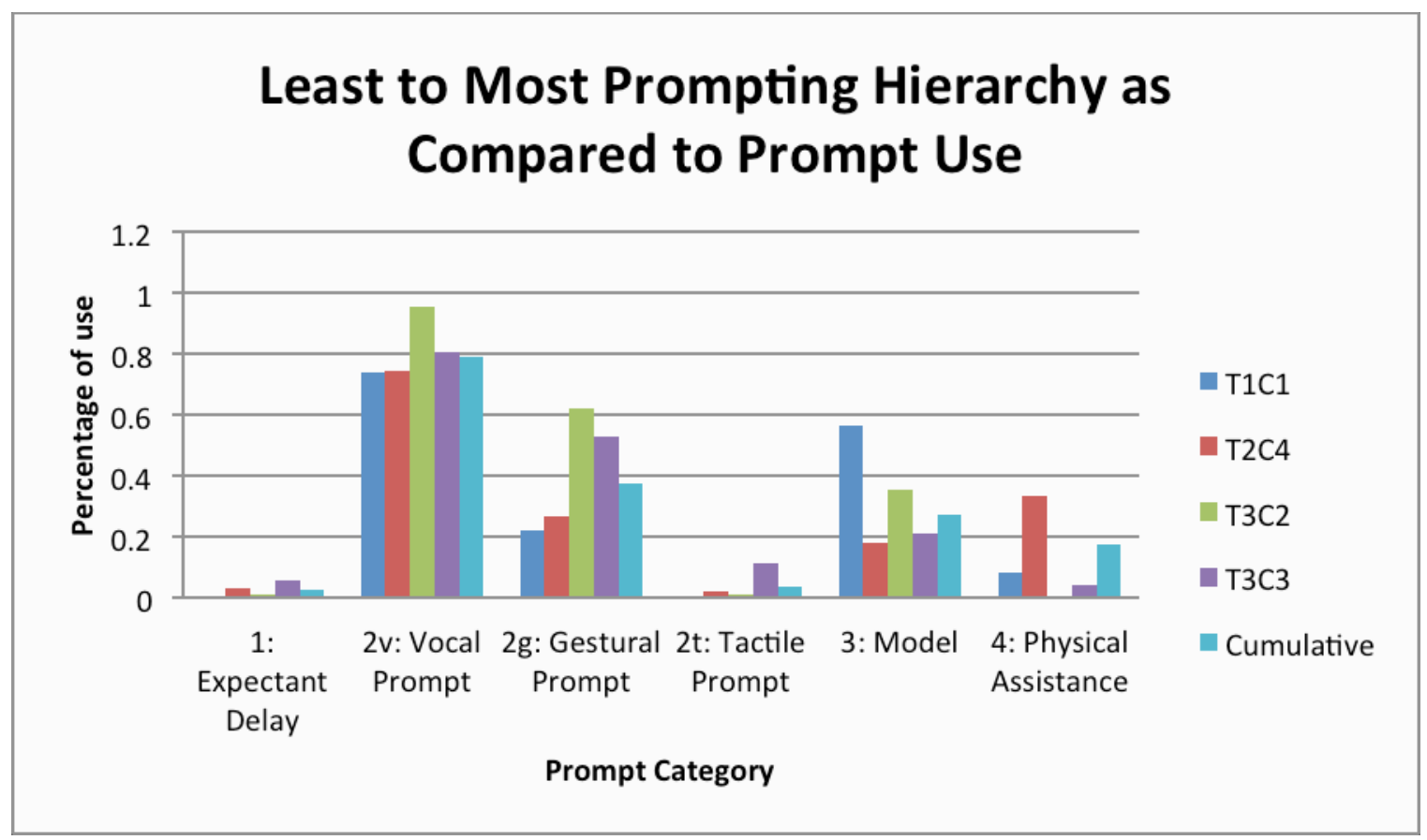

Figure 11. Least to Most Prompting Hierarchy as Compared to Prompt Use 
Interrater Reliability

In addition to complete coding of the data set completed by the author, 2 independent coders, an assistive technology specialist and a clinical psychologist who designed and implemented the original study from which tapes for the present inquiry were obtained, coded $20 \%$ of the data set, from which a $82.8 \%$ interrater reliability rating was reached. 


\section{CHAPTER V.}

\section{DISCUSSION}

\subsection{Components of Investigation}

The aim of this thesis was to explore the communication interactions between teachers and their very young students with communication disorders learning to use speech-generating devices (SGDs). The study was undertaken in an effort to add to the knowledge base of educators and those preparing educators to work with young children learning to use SGDs to communicate. Our area of exploration was the explicit intervention procedures, in particular the prompts and cues best-suited to the elicitation of intentional communicative acts.

In order to gain insight into teacher behavior in interaction with young students using SGDs, video recordings of 4 teacher-student dyads involving 4 children and 3 teachers were reviewed. Teacher prompts were identified and coded based on an ordinal scale adapted from the work of Light and Binger (1998). The results of the study help us understand teacher preferences in prompting and cueing and device use within the interactions, as well as describing the relationship between prompts used and device use and the elicitation of intentional communicative acts from children.

\subsection{General Discussion}

The first research question addressed which prompts were most utilized by teachers in their attempts to elicit communicative acts from their young students using SGDs. It was hypothesized that teachers would more frequently use prompts utilizing oral language than the

device. Results revealed that the use of oral language (coded as use of prompt level $2 \mathrm{v}$ - vocal) 
and device use were not mutually exclusive, and both were utilized frequently in the teacher's prompts $(79.27 \%$ and $70 \%$, respectively), and often $(66.51 \%)$ in combination.

With regard to overall frequency of prompts used, teachers used prompt category $2 \mathrm{v}$ (vocal) most frequently, in $79.27 \%$ of all prompts. As noted previously, the total percentages for each prompt category here exceeds 100 because teachers often used prompts in combination with one another. After prompt category $2 \mathrm{v}$, category $2 \mathrm{~g}$ (gestural), was used most frequently, $37.64 \%$ of the time, category 3 (model), used $27.45 \%$ of the time, and category 4 (physical assistance), used $17.45 \%$ of the time. By comparison, categories $2 \mathrm{t}$ (tactile prompt) and 1 (expectant delay) were employed relatively infrequently, in $3.82 \%$ and $2.91 \%$ of total prompts, respectively. These results are interesting in light of the recommendation from Light and Binger (1998), amongst others, that a "least-to-most" pattern be employed in prompting, in order to give the AAC user time to process and responds. Results of this study cast doubt on the likelihood that teachers are doing this, with the most intrusive category of prompting (4-physical assistance, the use of which nulls the opportunity for the child to intentionally respond) used much more frequently than category 1 (expectant delay), the most discreet form of prompting.

These results and interpretations generally hold when individual teacher-child dyads are explored, though subtle differences exist that merit further exploration. For example, category $2 \mathrm{v}$ vocal prompt was the most frequently used prompt for all teachers, with percentage of use ranging from $74.12 \%$ to $95.56 \%$ (overall use $=79.27 \%$ ). Percentage of use is consistently high across dyads, whereas the percentage of use for use of category 3-model varies greatly, ranging from $56.47 \%$ to $17.86 \%$. Likewise, category 4 - physical assistance is used as much as $33.33 \%$ of the time with one dyad, and not used at all in another. This variability within prompt category for teachers suggests that while teachers are talking consistently, even constantly, (prompt category $2 v$ ) in an effort to elicit communicative acts from the children, their other prompting behaviors 
are inconsistent and highly variable. As statistical analysis revealed prompting behavior did not affect the elicitation of communicative acts from children, the question as to what motivates teachers' prompting behavior remains.

Overall, teachers used the device in their prompting a majority of the time in both data sets and in conjunction with a variety of prompts: $64 \%$ in the data set excluding prompt level 4 (physical assistance; $n=455$ ) and $70 \%$ in the data set including prompt level 4 ( $n=550)$. The small discrepancy between these numbers is likely due to the fact that prompt level 4 always includes device use, as the teacher is physically guiding the child to activate the device for communication. Remarkably, teacher use of device in prompting is extremely consistent across dyads, with a range from $66.27 \%$ to $75.29 \%$. Since device use was shown not to impact the elicitation of communicative acts, this suggests that while teachers are often incorporating the device into their prompts, they need further instruction on how to effectively incorporate the device for communication elicitation.

The second inquiry asked which prompts would be more effective in eliciting communicative acts from children. While we hypothesized that prompts utilizing the device would be more effective, analysis revealed that device use was not a factor in communicative act elicitation. While teachers used the device consistently in their prompts, device use did not affect the elicitation of communicative acts from children.

Overall, and regardless of device use, there was no significance found between the level of prompt used and whether or not a communicative act was elicited from the child. These results suggest that children's communicative acts and responses are tied to variables outside the scope of this study, that the sample of prompts collected here was too small in size to demonstrate differences amongst prompt categories and/or that there was too much individual variability amongst children and teachers for which the methodology of the study could not control. 
Despite the fact that using one prompt over another does not appear to affect the elicitation of child communicative acts, teachers demonstrated an overwhelming preference for certain prompt categories (e.g. category 2- direct attention) while others (e.g. category 1expectant delay) were infrequently used. In the full data set (including category 4), category 2 direct attention prompts were involved in $83.64 \%$ of all prompts. Additionally, teachers showed a strong preference for category $2 \mathrm{v}$ - vocal prompts; a sub-analysis of category 2 prompts revealed that $65.55 \%$ of them involved vocal prompting. The ubiquity of vocal prompting, despite its failure to effect the elicitation of child communicative acts at a rate better than that which may occur by chance, suggests the teachers rarely stopped talking during the recorded interactions. This information corroborates previous research by Blackstone (1999) and Light, Collier and Parnes (1985) which found that communication partners in AAC interactions often dominate conversations, take the majority of conversational turns, provide insufficient time for individuals using $\mathrm{AAC}$ to respond and frequently interrupt the communication acts of AAC users.

Across dyads, there is a high rate of variability in the ultimate percentage of communicative acts elicited, ranging from $10.71 \%$ to $81.11 \%$. As prompting rates from teachers never vary so greatly as these percentages, it is likely that the children's individual communicative capacities played a great part in determining how often they respond in interactions.

\subsection{Limitations}

There are several limitations to take into account when interpreting the results of this study. First, convenience sampling was used to recruit participants, all of whom were students and teachers at the same university-based early childcare center. Given the small number of 
participants ( 4 children and 3 teachers, totaling 4 dyads), caution is advised in interpreting results and observations recorded here as representative of the greater population of either young children with CCN using SGDs or of their teacher's behavior within interactions. Also, a great degree of variability was seen amongst the performance of children in the study, indicating the differences in their individual linguistic and cognitive abilities, which was noted but not controlled for in the analysis.

Additionally, because of the teacher's infrequent use of some prompt categories (e.g. category 1- expectant delay) as compared to others, it should be noted that the statistical requirements for Pearson's chi-square test was not met for Test 1 ( 1 cell, or $16.7 \%$ had an expected count less than 5). Given the final results, it is unlikely that this gap in the data affected the outcome. Furthermore, due to child and teacher absence, the amount of interaction time received was not equivalent across participants, and the subsequent cumulative times recorded and coded are not comparable, creating a potentially confounding variable in this iteration of the data.

\subsection{Implications for Future Research}

Given the preponderance of certain categories of prompt use (e.g. 2-direct attention, $2 \mathrm{v}$ vocal prompt), and the existing research noting the conversation dominance and other weaknesses of communication partners in AAC interactions (Kent-Walsh \& McNaughton, 2005), the need for further treatment and implementation studies in the context of teacher-child dyads is paramount. Ideally, future studies can employ ABAB designs with multiple baseline measures that will allow researchers to isolate the effects of different types of prompts on the elicitation of child communicative acts. Existing studies in this area (see Romski, et al., 2015 for a review) tend to 
have small numbers of participants and insufficient control over children's developmental variables at the initiation of the studies.

Interestingly, teachers utilized the device with their prompting strategies more than was expected, though this did not appear to affect the children's overall rate of response. Future research should explore how device use can be incorporated with less-frequently used prompts (e.g. expectant delay) or strategies not included in this study (e.g. system presentation, as described by Carter, 2003) and whether this can affect child behavior.

\subsection{Summary and Conclusions}

While the extant research strongly endorses the use of AAC, and specifically SGDs, for young children with complex communication needs in early childhood education settings, the conception and development of implementation procedures and strategies remain scarce. Developmentally-appropriate ways in which teachers can scaffold their young students with communication disorders learning to use SGDs for communication remain an important line of inquiry for the field.

The current study adapted an existing hierarchy of prompts to examine teacher behavior and its relationship to the elicitation of communicative acts from young children using SGDs, with the goal of identifying best practices for future use. Statistical analysis revealed no difference between types of prompts used and their success in eliciting communicative acts from children. Likewise, while teachers frequently incorporated the SGDs with a variety of prompting strategies, device use was not found to impact the elicitation of communicative acts.

Descriptive analysis, however, revealed that the teachers in this study overwhelming relied on vocal forms of prompting and cueing, suggesting that the children were given little time 
to process and respond. This construct is further supported by the infrequent use of the expectant delay prompt, a time-delay procedure designed to provide additional time for processing and response. The great disparity observed between vocal and time-delay strategies despite the fact that neither appears to increase the likelihood of a child response, suggests at a minimum that teachers should employ a greater variety of prompting and cueing strategies when engaged as communication partners. Given the differences in linguistic, cognitive and motor processing observed in many children with complex communication needs, it is likely that both communication partners and SGD users will benefit from the opportunity to talk less and wait more. 


\section{REFERENCES}

Achenbach, T.M., \& Rescorla, L.A. (2000). Manual for the ASEBA Preschool Forms \& Profiles. Burlington, VT: University of Vermont, Research Center for Children, Youth \& Families.

American Speech-Language-Hearing Association. (2005). Roles and responsibilities of speechlanguage pathologists with respect to augmentative and alternative communication: Position statement. doi: 10.1044/policy.PS2005-00113

Banajee, M., Dicarlo, C., \& Stricklin, S. B. (2003). Core vocabulary determination for toddlers. AAC: Augmentative and Alternative Communication, 19(2), 67-73.

doi:http://dx.doi.org.ezproxy.fiu.edu/10.1080/0743461031000112034

Barker, R. M., Akaba, S., Brady, N. C., \& Thiemann-Bourque, K. (2013). Support for ACC use in preschool, and growth in language skills, for young children with developmental disabilities. AAC: Augmentative and Alternative Communication, 29(4), 334-346. doi:http://dx.doi.org.ezproxy.fiu.edu/10.3109/07434618.2013.848933

Barton, A., Sevcik, R. A., \& Romski, M. A. (2003). Exploring visual-graphic symbol acquisition by pre-school age children with developmental and language delays. AAC: Augmentative and Alternative Communication, 22(1), 10-20.

doi:http://dx.doi.org.ezproxy.fiu.edu/10.1080/07434610500238206

Beck, A. R., Stoner, J. B., \& Dennis, M. L. (2009). An investigation of aided language stimulation: Does it increase AAC use with adults with developmental disabilities and complex communication needs? AAC: Augmentative and Alternative Communication, 25(1), 42-54. doi:http://dx.doi.org.ezproxy.fiu.edu/10.1080/07434610802131059

Beukelman, D. R. (1991). Magic and cost of communicative competence. AAC: Augmentative and Alternative Communication, 7(1), 2-10. Retrieved from http://ezproxy.fiu.edu/login?url=http://search.proquest.com.ezproxy.fiu.edu/docview/617963914? accountid=10901

Beukelman, D.R. \& Mirenda, P. (2013). Augmentative and alternative communication:

Supporting children and adults with complex communication needs. Baltimore: Paul H. Brookes.

Blackstone, S. (1999). Clinical News: Communication Partners. Augmentative Communication News, 12(1) 1-3. 
Boesch, M. C., Wendt, O., Subramanian, A., \& Hsu, N. (2013). Comparative efficacy of the picture exchange communication system (PECS) versus a speech-generating device: Effects on social-communicative skills and speech development. AAC: Augmentative and Alternative Communication, 29(3), 197-209.

doi:http://dx.doi.org.ezproxy.fiu.edu/10.3109/07434618.2013.818059

Bondy, A., \& Frost, L. (2002). A picture's worth: PECS and other visual communication strategies in autism Woodbine House, Bethesda, MD. Retrieved from http://ezproxy.fiu.edu/login?url=http://search.proquest.com.ezproxy.fiu.edu/docview/619711695? accountid=10901

Brady, N. C., Thiemann-Bourque, K., Fleming, K., \& Matthews, K. (2013). Predicting language outcomes for children learning augmentative and alternative communication: Child and environmental factors. Journal of Speech, Language, and Hearing Research, 56(5), 1595-1612. doi:http://dx.doi.org.ezproxy.fiu.edu/10.1044/1092-4388(2013/12-0102)

Bryen, D. N., Carey, A., \& Frantz, B. (2003). Ending the silence: Adults who use augmentative communication and their experiences as victims of crimes. AAC: Augmentative and Alternative Communication, 19(2), 125-134.

doi:http://dx.doi.org.ezproxy.fiu.edu/10.1080/0743461031000080265

Carter, M. (2003). Communicative spontaneity of children with high support needs who use augmentative and alternative communication systems II: Antecedents and effectiveness of communication. AAC: Augmentative and Alternative Communication, 19(3), 155-169. doi:http://dx.doi.org.ezproxy.fiu.edu/10.1080/0743461031000112025

Caves, K., Shane, H.C., \& DeRuyter, F. (2002). Connecting AAC devices to the world of information technology. Assistive Technology, 14, 81-89.

Center for AAC \& Autism. (2009). What is Lamp? Retrieved from http://www.aacandautism.com/lamp

Collier, B., \& Self, H. (2010). Preparing youth who use AAC to communicate with their personal assistants. In D. McNaughton \& D. Beukelman (Eds.), Transition strategies for adolescents and adults who use AAC (pp. 163-180). Baltimore, MD: Paul H. Brookes.

Collier, B., McGhie-Richmond, D., Odette, F., \& Pyne, J. (2006). Reducing the risk of sexual abuse for people who use augmentative and alternative communication. AAC: Augmentative and 
Alternative Communication, 22(1), 62-75.

doi:http://dx.doi.org.ezproxy.fiu.edu/10.1080/07434610500387490

Dicarlo, C. F., \& Banajee, M. (2000). Using voice output devices to increase initiations of young children with disabilities. Journal of Early Intervention, 23(3), 191-199.

doi:http://dx.doi.org.ezproxy.fiu.edu/10.1177/10538151000230030801

Foley, B.E., \& Wolter, J. (2010). Literacy intervention for transition-aged youth: What it is and what it could be. In D. McNaughton, \& D. Beukelman, (Eds.), Transition strategies for adolescents and young adults who use AAC (pp.35-68). Baltimore, MD: Paul H Brookes.

Gadberry, A. L. (2012). Client communicative acts and therapist prompts with and without aided augmentative and alternative communication systems. Music Therapy Perspectives, 30(2), 151157. Retrieved from

http://ezproxy.fiu.edu/login?url=http://search.proquest.com.ezproxy.fiu.edu/docview/1433275648 ?accountid=10901

Ganz, J. B., Earles-Vollrath, T., Heath, A. K., Parker, R. I., Rispoli, M. J., \& Duran, J. B. (2012). A meta-analysis of single case research studies on aided augmentative and alternative communication systems with individuals with autism spectrum disorders. Journal of Autism and Developmental Disorders, 42(1), 60-74. doi:http://dx.doi.org.ezproxy.fiu.edu/10.1007/s10803011-1212-2

Ganz, J. B., Rispoli, M. J., Mason, R. A., \& Hong, E. R. (2014). Moderation of effects of AAC based on setting and types of aided AAC on outcome variables: An aggregate study of single-case research with individuals with ASD. Developmental Neurorehabilitation, 17(3), 184-192. doi:http://dx.doi.org.ezproxy.fiu.edu/10.3109/17518423.2012.748097

Hancock, T. B., \& Kaiser, A. P. (2002). The effects of trainer-implemented enhanced milieu teaching on the social communication of children with autism. Topics in Early Childhood Special Education, 22(1), 39-54. doi:http://dx.doi.org.ezproxy.fiu.edu/10.1177/027112140202200104

Harris, M. D., \& Reichle, J. (2004). The impact of aided language stimulation on symbol comprehension and production in children with moderate cognitive disabilities. American Journal of Speech-Language Pathology, 13(2), 155-167. doi:http://dx.doi.org.ezproxy.fiu.edu/10.1044/1058-0360(2004/016)

Houtrow, A. J., Larson, K., Olson, L. M., Newacheck, P. W., \& Halfon, N. (2014). Changing trends of childhood disability, 2001-2011. Pediatrics, 134(3), 530-538.

doi:http://dx.doi.org.ezproxy.fiu.edu/10.1542/peds.2014-0594 
Iacono, T. A., \& Duncum, J. E. (1995). Comparison of sign alone and in combination with an electronic communication device in early language intervention: Case study. AAC: Augmentative and Alternative Communication, 11(4), 249-254. Retrieved from http://ezproxy.fiu.edu/login?url=http://search.proquest.com.ezproxy.fiu.edu/docview/618944830? accountid=10901

Johnston, S. S., McDonnell, A. P., Nelson, C., \& Magnavito, A. (2003). Teaching functional communication skills using augmentative and alternative communication in inclusive settings. Journal of Early Intervention, 25(4), 263-280.

doi:http://dx.doi.org/10.1177/105381510302500403

Kagohara, D. M., van, d. M., Ramdoss, S., O’Reilly, M. F., Lancioni, G. E., Davis, T. N., Rispoli, M., Lang, R., Marschik, P.B., Sutherland, D., Green, V.A., Sigafoos, J. (2013). Using iPods ${ }^{\circledR}$ and iPads ${ }^{\circledR}$ in teaching programs for individuals with developmental disabilities: A systematic review. Research in Developmental Disabilities, 34(1), 147-156.

doi:http://dx.doi.org/10.1016/j.ridd.2012.07.027

Kent-Walsh, J., \& McNaughton, D. (2005). Communication partner instruction in AAC: Present practices and future directions. AAC: Augmentative and Alternative Communication, 21(3), 195204. doi:http://dx.doi.org.ezproxy.fiu.edu/10.1080/07434610400006646

Light, J. (1989). Toward a definition of communicative competence for individuals using augmentative and alternative communication systems. AAC: Augmentative and Alternative Communication, 5(2), 137-144. Retrieved from http://ezproxy.fiu.edu/login?url=http://search.proquest.com.ezproxy.fiu.edu/docview/617631186? accountid $=10901$

Light, J. (1997-01). "Communication is the essence of human life": reflections on communicative competence. Augmentative and alternative communication, 13(2), 61-

70.doi:10.1080/07434619712331277848 This article is not available online, took reference Light \& McNaughton, 2012 article

Light, J. (2003). Shattering the silence: Development of communicative competence by individuals who use AAC. In J.C. Light, D.R. Beukelman, \& J. Reichle (Eds.), Communicative competence for individuals who use AAC: From research to effective practice (pp. 3-38). Baltimore, MD: Paul H. Brookes.

Light, J.C., \& Binger, C. (1998). Building communicative competence with individuals who use augmentative and alternative communication. Baltimore, MD: Paul H. Brookes.

Light, J., Collier, B., \& Parnes, P. (1985). Communicative interaction between young nonspeaking physically disabled children and their primary caregivers: I. discourse patterns. AAC: Augmentative and Alternative Communication, 1(2), 74-83. Retrieved from 
http://ezproxy.fiu.edu/login?url=http://search.proquest.com.ezproxy.fiu.edu/docview/617446844? accountid=10901

Light, J., \& McNaughton, D. (2012). The changing face of augmentative and alternative communication: Past, present, and future challenges. AAC: Augmentative and Alternative Communication, 28(4), 197-204.

doi:http://dx.doi.org.ezproxy.fiu.edu/10.3109/07434618.2012.737024

Light, J., \& McNaughton, D. (2014). Communicative competence for individuals who require augmentative and alternative communication: A new definition for a new era of communication? AAC: Augmentative and Alternative Communication,30(1), 1-18. doi:http://dx.doi.org.ezproxy.fiu.edu/10.3109/07434618.2014.88508

Light, J., \& McNaughton, D. (2015). Designing AAC research and intervention to improve outcomes for individuals with complex communication needs. AAC: Augmentative and Alternative Communication, 31(2), 85-96. doi:http://dx.doi.org.ezproxy.fiu.edu/10.3109/07434618.2015.1036458

Matson, J. L., \& Wilkins, J. (2007). A critical review of assessment targets and methods for social skills excesses and deficits for children with autism spectrum disorders. Research in Autism Spectrum Disorders, 1(1), 28-37.

doi:http://dx.doi.org.ezproxy.fiu.edu/10.1016/j.rasd.2006.07.003

McNaughton, D., Bryen, D., Blackstone, S., Williams, M., \& Kennedy, P. (2012). Young adults with complex communication needs: Research and development in AAC for a "diverse" population. Assistive Technology, 24(1), 45-53.

doi:http://dx.doi.org.ezproxy.fiu.edu/10.1080/10400435.2011.648715

McNaughton, D., \& Light, J. (1989). Teaching facilitators to support the communication skills of an adult with severe cognitive disabilities: A case study. AAC: Augmentative and Alternative Communication, 5(1), 35-41. Retrieved from

http://ezproxy.fiu.edu/login?url=http://search.proquest.com.ezproxy.fiu.edu/docview/617625036? accountid=10901

McNaughton, D., \& Light, J. (2013). The iPad and mobile technology revolution: Benefits and challenges for individuals who require augmentative and alternative communication. $A A C$ : Augmentative and Alternative Communication, 29(2), 107-116. doi:http://dx.doi.org.ezproxy.fiu.edu/10.3109/07434618.2013.784930

McNaughton, D., Light, J., \& Arnold, K. (2002). "Getting your wheel in the door": The full-time employment experiences of individuals with cerebral palsy who use AAC. Augmentative and Alternative Communication, 18, 59-76. doi: 10.1080/07434610212331281171 
Millar, D. C., Light, J. C., \& Schlosser, R. W. (2006). The impact of augmentative and alternative communication intervention on the speech production of individuals with developmental disabilities: A research review. Journal of Speech, Language, and Hearing Research, 49(2), 248264. Retrieved from http://ezproxy.fiu.edu/login?url=http://search.proquest.com.ezproxy.fiu.edu/docview/621730656? accountid=10901

National Center for Education Statistics (2013). Percentage distribution of students 6 to 21 years old served under Individuals with Disabilities Education Act (IDEA), Part B, by educational environment and type of disability: Selected years, fall 1989 through fall 2011. United States Department of Education Institute of Education Sciences.

https:nces.ed.gov/programs/digest/d13/tables/dt13_204.60.asp

National Joint Committee for the Communication Needs of Persons with Severe Disabilities (2003). Supporting documentation for the position statement on access to communication services and supports: Concerns regarding the application of restrictive eligibility policies. ASHA Supplement, 23, 73-81.

Paul, R. \& Norbury, C. (2012). Language disorders: From infancy to adolescence. St. Louis, MO: Elsevier Mosby

Reichle, J. E., York, J., \& Sigafoos, J. (1991). Implementing augmentative and alternative communication: Strategies for learners with severe disabilities Paul H Brookes Publishing, Baltimore, MD. Retrieved from

http://ezproxy.fiu.edu/login?url=http://search.proquest.com.ezproxy.fiu.edu/docview/618394612? accountid $=1090$

Rispoli, M. J., Franco, J. H., van, d. M., Lang, R., \& Camargo, S. (2010). The use of speech generating devices in communication interventions for individuals with developmental disabilities: A review of the literature. Developmental Neurorehabilitation, 13(4), 276-293. doi:http://dx.doi.org.ezproxy.fiu.edu/10.3109/17518421003636794

Romski, M., Sevcik, R. A., Adamson, L. B., Cheslock, M., Smith, A., Barker, R. M., \& Bakeman, R. (2010). Randomized comparison of augmented and non-augmented language interventions for toddlers with developmental delays and their parents. Journal of Speech, Language, and Hearing Research, 53(2), 350-364. doi:http://dx.doi.org.ezproxy.fiu.edu/10.1044/1092-4388(2009/08-0156)

Romski, M., Sevcik, R. A., Barton-Hulsey, A., \& Whitmore, A. S. (2015). Early intervention and AAC: What a difference 30 years makes. AAC: Augmentative and Alternative 
Communication, 31(3), 181-202.

doi:http://dx.doi.org.ezproxy.fiu.edu/10.3109/07434618.2015.1064163

Rogers, S. J., \& Dawson, G. (2010). Early start denver model for young children with autism: Promoting language, learning, and engagement Guilford Press, New York, NY. Retrieved from http://ezproxy.fiu.edu/login?url=http://search.proquest.com.ezproxy.fiu.edu/docview/622227402? accountid $=10901$

Rowland, C. (2009). Online communication matrix. Portland: Oregon Health \& Science University, Design to Learn Projects Retrieved from http://communicationmatrix.org

Rowland, C. \& Schweigert, P.D. (2003). Cognitive skills and AAC. In J.C. Light, D.R. Beukelman, \& J. Reichle (Eds.), Communicative competence for individuals who use AAC: From research to effective practice (pp.241-275). Baltimore: Paul H. Brookes.

Schladant, M. (2012). Parent perspectives on communication and use of augmentative and alternative communication systems in children with fragile $X$ syndrome (Order No.

AAI3456361). Available from PsycINFO. (993099245; 2012-99030-248). Retrieved from http://ezproxy.fiu.edu/login?url=http://search.proquest.com.ezproxy.fiu.edu/docview/993099245? accountid $=10901$

Schladant, M., Dowling, M., Coron, C., Nevares, A., \& Toro, M. (2014, July). iCanChat project: creating meaningful language experiences through AAC for children with complex communication needs. Paper presented at the biennial meeting of the International Society for AAC, Lisbon, Portugal.

Schlosser, R. W. (2003). The efficacy of augmentative and alternative communication: Toward evidence-based practice Academic Press, San Diego, CA. Retrieved from http://ezproxy.fiu.edu/login?url=http://search.proquest.com.ezproxy.fiu.edu/docview/620864539? accountid $=10901$

Schlosser, R. W., \& Wendt, O. (2008). Effects of augmentative and alternative communication intervention on speech production in children with autism: A systematic review. American Journal of Speech-Language Pathology, 17(3), 212-230.

doi:http://dx.doi.org.ezproxy.fiu.edu/10.1044/1058-0360(2008/021)

Shire, S. Y., \& Jones, N. (2015). Communication partners supporting children with complex communication needs who use AAC: A systematic review. Communication Disorders Quarterly, 37(1), 3. Retrieved from http://ezproxy.fiu.edu/login?url=http://search.proquest.com/docview/1732574727?accountid=109 01

Sigafoos, J., \& Drasgow, E. (2001). Conditional use of aided and unaided AAC: A review and clinical case demonstration. Focus on Autism and Other Developmental Disabilities, 16(3), 152- 
161. Retrieved from

http://ezproxy.fiu.edu/login?url=http://search.proquest.com.ezproxy.fiu.edu/docview/619701680? accountid=10901

Sigafoos, J., Green, V. A., Payne, D., Son, S., O'Reilly, M., \& Lancioni, G. E. (2009). A comparison of picture exchange and speech-generating devices: Acquisition, preference, and effects on social interaction. AAC: Augmentative and Alternative Communication, 25(2), 99-109. doi:http://dx.doi.org.ezproxy.fiu.edu/10.1080/07434610902739959

Solomon-Rice, P., \& Soto, G. (2014). Facilitating vocabulary in toddlers using AAC: A preliminary study comparing focused stimulation and augmented input. Communication Disorders Quarterly, 35(4), 204-215.

doi:http://dx.doi.org.ezproxy.fiu.edu/10.1177/1525740114522856

United States Department of Education. (2011). Historical State-Level IDEA Data Files [Part C Child Count]. Retrieved from http://tadnet.public.tadnet.org/pages/712.

Waddington, H., Sigafoos, J., Lancioni, G. E., O’Reilly, M. F., van, d. M., Carnett, A., Stevens, M., Roche, L., Hodis, F., Green, V., Sutherland, D., Lang, R., \&Marschik, P. B. (2014). Three children with autism spectrum disorder learn to perform a three-step communication sequence using an $\mathrm{iPad} \AA$-based speech-generating device. International Journal of Developmental

Neuroscience, 39, 59-67. doi:http://dx.doi.org.ezproxy.fiu.edu/10.1016/j.ijdevneu.2014.05.001 
APPENDIX A. Coding Protocol for Teacher Prompt and Child Communicative Acts

\begin{tabular}{|c|c|c|c|c|c|}
\hline \multicolumn{6}{|c|}{ Coding of Teacher Prompts and Child Communicative Acts } \\
\hline Time Stamp & Prompt & Device & Child & Notes & KEY \\
\hline & & & & & Prompts \\
\hline & & & & & $1=$ expectant delay \\
\hline & & & & & $2=$ directing attention $(2 \mathrm{G}=$ \\
\hline & & & & & gestural; $2 \mathrm{~V}=$ vocal; $2 \mathrm{~T}=$ tactile) \\
\hline & & & & & $3=$ model \\
\hline & & & & & $4=$ full physical guidance \\
\hline & & & & & \\
\hline & & & & & Device \\
\hline & & & & & $1=$ device utilized in prompt \\
\hline & & & & & $0=$ no device used in prompt \\
\hline & & & & & Child \\
\hline & & & & & $1=$ communicative act elicited \\
\hline & & & & & $0=$ no communicative act elicited \\
\hline & & & & & \\
\hline & & & & & Adapted from \\
\hline & & & & & Light \& Binger, 1998 \\
\hline & & & & & \\
\hline & & & & & \\
\hline & & & & & \\
\hline & & & & & \\
\hline & & & & & \\
\hline & & & & & \\
\hline & & & & & \\
\hline & & & & & \\
\hline & & & & & \\
\hline & & & & & \\
\hline & & & & & \\
\hline & & & & & \\
\hline & & & & & \\
\hline & & & & & \\
\hline & & & & & \\
\hline & & & & & \\
\hline & & & & & \\
\hline & & & & & \\
\hline
\end{tabular}


Appendix B. Informed Consent-Children/Families

\section{iCan Chat Project}

\section{DEBBIE SCHOOL INFORMED CONSENT}

The following information describes the research study in which you and your child are being asked to participate. Please read the information carefully, and ask questions about anything you do not understand before deciding whether or not you and your child may participate. At the end, you will be asked to sign if you agree to participate and to allow your child to participate. You and your child's participation are voluntary.

\section{PURPOSE OF STUDY}

We want to inform you of a new research project at the Debbie School. The project is called iCan Chat and involves creating meaningful language experiences through assistive technology. The iCan Chat project will look at how assistive technology such as the iPad can help to promote opportunities for your children to communicate and interact with others, as well as participate more in daily classroom routines. The research will evaluate your child's progress and the effectiveness of the technology.

To participate in this study you must have a child with autism or related disorder such as intellectually disability, fragile $\mathrm{X}$ syndrome, or language impairment who is not yet talking or talking very little. You must be English-speaking.

\section{DURATION AND LOCATION}

Your participation in this study will last while your child is in the Debbie School and will take place during school hours in your child's classroom with your child's teachers or in therapy with your child's speech therapist.

\section{PROCEDURES}

If you agree to participate in this study, there will be three parts to this research. One part of the research involves evaluation of your child's communication development by a trained researcher. The evaluation will be conducted during school hours and is very similar to how teachers and/or therapists evaluate your child's progress. The assessment will take place while your child is in school and will last less than an hour. During the evaluation, the researcher will sit with your child and present some common items to your child, such as familiar toys, books, 
and other play materials. She will then either see what your child does or ask your child to perform a certain task. Then she records what your child has done. The children will be evaluated at the beginning of the project and at the end of each school year while your child is enrolled at the Debbie School. We will also use the assessments that have been completed by your child's teachers and therapists. This information will

help us follow your child's development while he/she is in the Debbie School program.

To assist with the evaluation process, research staff may need to access your child's school records to obtain information. This information will include demographic information, race and level of household income, your child's birth date, and the nature of his/her disability. This information is obtained for the purpose of describing the school population, and information will be reported as part of a group. No individual demographic information will be reported in research findings.

The second part of this study involves your child being observed by a researcher to see how the technology is helping your child to communicates and interact with others. The researcher will observe your child in his or her classroom during regular school hours.

For the last part of this study, we would also like to receive input from parents and other caregivers. We will ask you as well as your child's teacher and speech therapist to complete checklists on how your child communicates and behaves and questionnaires on how we can use technology to promote communication and social interactions with others in the classroom and at home. Some questions might be....

${ }_{17}^{35}$ How does your child communicate and behave?

${ }_{17}^{35}$ What would you like your child to be able to communicate?

${ }_{17}^{35}$ How does your child play and interact with others?

${ }_{17}^{35}$ What is your child's favorite toy/ theme

We would also like permission to take pictures of your child and videotape him or her in the classroom. This would be to show how we use technology to help young children communicate. For example, we may take a picture or videotape your child using an iPad with a special app that talks to make choices during snack time. We will use these pictures and videos in our school manual, in newsletters, in project reports for future funding, and for presentations to parents, as well as to students and professionals who are learning how to work with children. We will not identify your child by name in these pictures or videotapes. We will destroy any pictures and videos that we are not using one year after the end of this project.

\section{POTENTIAL RISKS AND DISCOMFORTS}

There are no anticipated health or social risks to you or your child for participating. The research will not change your child's current program. We will simply be examining child progress. 


\section{ANTICIPATED BENEFITS}

While your child may not benefit directly from participation in this study, you will be helping the field of early childhood education. You will help us collect information that may help other children benefit from assistive technology.

\section{CONFIDENTIALITY}

The investigators and their assistants will consider your records confidential to the extent permitted by law. Your records may also be reviewed for audit purposes by authorizes University of Miami employees, The Department of Health and Human Services (DHHS) or other agents who must follow the same rules of confidentiality. Names will not be used in the reporting of information in any publication. The results of the study will be reported as group results and any individual results that are reported will not use names in order to protect your child's identity.

\section{COMPENSATION}

During the study your child will be using a refurbished iPad with a special communication app and a case. This device was donated by the Florida Alliance for Assistive Services and Technology South Florida Regional Demonstration Program located at the Mailman Center for Child Development. You will receive the iPad at the end of the project for your participation in the study. If you decide to withdraw your child from the study at any time you will receive the iPad at that time.

\section{VOLUNTARY PARTICIPATION}

Participation in this study is voluntary. Saying "no" to this study or any part of the study will not affect in any way the services you and your child receive at the Debbie School. You may also withdraw your child from the study at any time without penalty or punishment or any effect whatsoever on your child's care.

\section{QUESTIONS}

If you have any questions regarding this study, please contact Dr. Michelle Schladant, Co-Investigator (305-243-4466) or Dr. Monica Dowling (305-243-6857), Primary Investigator of the study. If you have any questions about your right as a research participant, you may call the University of Miami Human Subject Research Office, at 305-243-3195.

Please complete the form on the following page. A signed copy of this form will be returned to you. 


\section{iCan Chat Project}

\section{DEBBIE SCHOOL INFORMED CONSENT}

\section{PARTICIPANT AGREEMENT}

I have read the information in this consent form and agree for me and my child to participate in this study. I have had the chance to ask any questions I have about this study, and they have been answered for me. I am entitled to a copy of this form after it has been read and signed.

Your Name

(Please print your name)

Your Child's Name

(Please print your child's name)

I agree to allow my child to participate in the research component of the iCan Chat Project

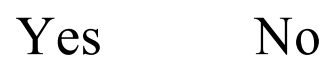

I agree to allow my child to be photographed and videotaped, and for these pictures and videos to be used and stored as stated in this consent form.

Yes $\quad$ No

Date 
Appendix C: Informed Consent- Teachers

\section{iCan Chat Project}

\section{STAFF INFORMED CONSENT}

The following information describes the research study in which you are being asked to participate. Please read the information carefully, and ask questions about anything you do not understand before deciding whether or not to participate. At the end, you will be asked to sign if you agree to participate. Your participation is voluntary.

\section{PURPOSES OF STUDY}

We want to inform you of a new research project at the Debbie School. The project is called iCan Chat that involves creating meaningful language experiences through assistive technology. The iCan Chat project will look at how assistive technology such as the iPad can help children with autism and related disorders to improve communication and behavior, as well as to promote more positive interactions with others. The research will evaluate the progress of children in the study and the effectiveness of the technology.

\section{DURATION AND LOCATION}

Your participation in this study will last while the children in the study are in Debbie School and will take place during school hours in your classroom or in therapy with the child's therapist.

\section{PROCEDURE}

If you agree to be part of the iCan Chat Project, you will receive coaching and training on how to use assistive technology to help children to improve communication, behavior, and social interactions. We will ask you to complete some checklists to assess the child's communication, behavior, and social skills and questionnaires to assess your knowledge and views about assistive technology at the beginning and end of the project. In addition, for each child participating in the study you will be asked to (1) regularly collaborate with the children's school team (i.e., teachers, therapists) and parents to develop an AT plan; (2) keep a log of AT use; and (3) complete a case study for each child at the end of the study.

This study also involves the child being observed by a researcher to see how the technology is helping the child to communicates and interact with others. The researcher will also observe how you are using the technology to support the child's development of communication and social skills. The researcher will observe the child in his or her classroom or in therapy during regular school hours. 


\section{RISKS}

There are no anticipated health or social risks to you for participating. If any of the questions we ask make you feel uncomfortable, you may feel free to skip them. You may feel uncomfortable or nervous while being observed. If at any time you feel uncomfortable, you are free to stop at anytime.

\section{BENEFITS}

While your child may not benefit directly from participation in this study, you will be helping the field of early childhood education. You will help us collect information that may help other children benefit from assistive technology.

\section{CONFIDENTIALITY}

The investigators and their assistants will consider your records confidential to the extent permitted by law. Your records may also be reviewed for audit purposes by authorizes University of Miami employees, The Department of Health and Human Services (DHHS), or other agents who must follow the same rules of confidentiality. Names will not be used in the reporting of information in any publication. The results of the study will be reported as group results. Any individual results that are reported will not use names in order to protect your identity.

\section{VOLUNTARY PARTICIPATION}

Participation in this study is voluntary. Saying "no" to this study or any part of the study will not affect in any way your position at the Debbie School. You may also withdraw from the study at any time without penalty or punishment or any effect on your position.

\section{QUESTIONS}

If you have any questions regarding this study, please contact Dr. Michelle Schladant, Co-Investigator (305-243-4466) or Dr. Monica Dowling (305-243-6857), Primary Investigator of the study. If you have any questions about your right as a research participant, you may call the University of Miami Human Subject Research Office, at 305-243-3195.

Please complete the form on the following page: A copy of this form will be returned to you. 
agree to fully participate in the iCan Chat Project by keeping a log of the Assistive Technology use of children enrolled in the project and completing the staff questionnaires as described above.

or

I agree to participate in the iCan Chat Project by keeping a log of the Assistive Technology use of children enrolled in the project but I do $\underline{\text { NOT }}$ want to participate in the staff questionnaires as described above.

(Please print your name)

(Signature)

(Date) 
Appendix D. Copy of Institutional Board Review Approval

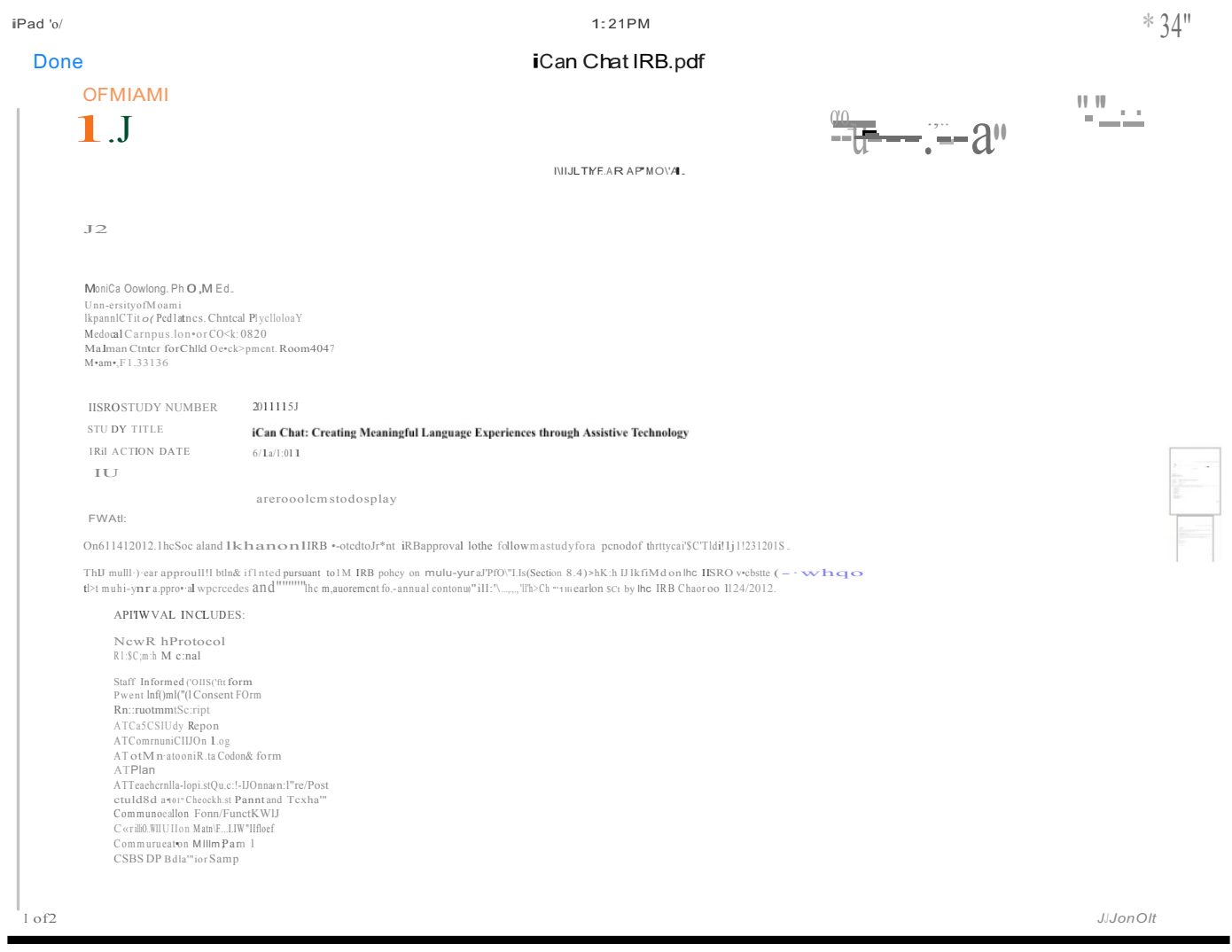


$\mathrm{iPad}$ ร

1:22 PM

iCan Chat IRB.pdf

1 of 2

$34 \%$

$[\uparrow]$

https://eprostarchive.med.miami.edu/Eprost/Doc/0/OPHB5J9RBPT4F8G46MOERSP09

$$
\begin{aligned}
& \text { CSBS DP Caregiver Questionain } \\
& \text { Interest Inventory } \\
& \text { LAMP Summary Form } \\
& \text { Parent Survey Post } \\
& \text { Parent Survey Pre }
\end{aligned}
$$

During this threc-year approval period, the study mus remain unchanged from that reviewed and approved by the IRB with the exception of amendments approved in accordance with Section 11 of the IRB policies. If an

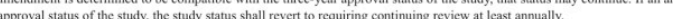

Pursuant to the IRB policy, study continuance requires that the principal investigator annually submit to the IRB hisher affimation that

a. The study protocol is unchanged from that granted multi-year approval by the IRB

b. The risk to subjects is unchanged

c. No study-related, serious adverse events occurred

As with other studies requiring continuing review, notices shall be forwarded to the Principal Investigator from the HSRO alerting them that the Principal Investigator Affirmation is due. If the affirmation is not received pries to or on the day at which IRB approval would have expired had the study not been given three-ycar approval, the study shall be suspended for expiration of IRB approval. NOTE - if affirmation of the above conditions canne be made by the principal investigator, a continuing report must be submitted

Please remember that the Human Subjects Rescarch Office (HSRO) must be notified of any proposed changes in research activities. Changes must receive IRB review and approval prior to implementation.

NOTE: Translations of IRB approved study documents, including informed consent documents, into languages other than English must be submitted to HSRO for approval prior to use

A request to continue this study must be submitted to the HSRO at least 45 days before IRB approval expires. If this study does not receive continuing IRB approval prior to expiration, all research activities must cease, and it nay be officially suspended or termintest

Sincerely.

[This is a rppresentation of an electronic recond

that was signed electronicalty and his pageris

Amanda Coltes-Rojas, MPH, CIP

Director

ce: IRB File

There are no items to display 
Appendix E. Raw Data from all Teacher-Child Dyads

\begin{tabular}{|c|c|c|c|c|c|}
\hline Prompt & De & & $\mathrm{Ch}$ & & \\
\hline $2 \mathrm{v}$ & 0 & & & 1 & KEY \\
\hline $3,2 \mathrm{v}$ & & 1 & & 1 & Prompts \\
\hline $3,2 \mathrm{v}$ & & 1 & & 1 & $1=$ expectant delay \\
\hline $3,2 \mathrm{v}$ & & 1 & & 1 & $2=$ directing attention $(2 \mathrm{G}=$ gestural $; 2 \mathrm{~V}=$ \\
\hline $2 \mathrm{v}$ & 0 & & & 1 & vocal; $2 \mathrm{~T}=$ tactile) \\
\hline $2 g$ & 0 & & & 1 & $3=$ model \\
\hline $2 \mathrm{~g}$ & 0 & & & 1 & $4=$ full physical guidance \\
\hline $2 \mathrm{~g}$ & & 1 & & 1 & \\
\hline 3 & & 1 & 0 & & Device \\
\hline 3 & & 1 & 0 & & $1=$ device utilized in prompt \\
\hline 3 & & 1 & 0 & & $0=$ no device used in prompt \\
\hline 3 & & 1 & 0 & & Child \\
\hline 3 & & 1 & 0 & & $1=$ communicative act elicited \\
\hline $2 \mathrm{v}, 2 \mathrm{~g}$ & 0 & & 0 & & $0=$ no communicative act elicited \\
\hline 3 & & 1 & & 1 & \\
\hline $2 \mathrm{v}, 2 \mathrm{~g}$ & & 1 & & 1 & Adapted from \\
\hline $2 \mathrm{v}$ & 0 & & & 1 & Light \& Binger, 1998 \\
\hline $2 \mathrm{v}, 3$ & & 1 & 0 & & \\
\hline $2 \mathrm{v}, 2 \mathrm{~g}$ & 0 & & & 1 & \\
\hline $2 \mathrm{v}, 3$ & & 1 & 0 & & \\
\hline $2 \mathrm{v}, 2 \mathrm{~g}$ & 0 & & & 1 & \\
\hline $3,2 \mathrm{v}$ & & 1 & & 1 & \\
\hline $2 \mathrm{v}$ & 0 & & 0 & & \\
\hline $2 \mathrm{v}, 3$ & & 1 & & 1 & \\
\hline $2 \mathrm{v}$ & 0 & & & 1 & \\
\hline 3 & & 1 & & 1 & \\
\hline $\begin{array}{l}3,2 \mathrm{v} \\
2 \mathrm{~g}\end{array}$ & & 1 & & 1 & \\
\hline $2 \mathrm{v}, 3$ & & 1 & & 1 & \\
\hline $2 \mathrm{v}, 3$ & & 1 & & 1 & \\
\hline $2 \mathrm{v}, 3$ & & 1 & & 1 & \\
\hline $2 \mathrm{v}, 3$ & & 1 & & 1 & \\
\hline $2 \mathrm{v}, 3$ & & 1 & & 1 & \\
\hline $2 \mathrm{v}, 2 \mathrm{~g}$ & 0 & & & 1 & \\
\hline 3 & & 1 & & 1 & \\
\hline 3 & & 1 & & 1 & \\
\hline $2 \mathrm{v}, 2 \mathrm{~g}$ & 0 & & & 1 & \\
\hline $2 \mathrm{v}, 2 \mathrm{~g}$ & 0 & & 0 & & \\
\hline
\end{tabular}




\begin{tabular}{|c|c|c|c|c|}
\hline Prompt & De & & & \\
\hline $2 \mathrm{v}, 3$ & & 1 & & 1 \\
\hline $2 \mathrm{v}, 2 \mathrm{~g}$ & & 1 & & 1 \\
\hline $2 \mathrm{v}$ & 0 & & 0 & \\
\hline $2 \mathrm{v}$ & 0 & & 0 & \\
\hline 3 & & 1 & & 1 \\
\hline $2 \mathrm{~g}, 2 \mathrm{v}$ & & 1 & 0 & \\
\hline 4 & & 1 & 0 & \\
\hline 4 & & 1 & 0 & \\
\hline $2 \mathrm{v}, 3$ & & 1 & 0 & \\
\hline 3 & & 1 & 0 & \\
\hline $2 \mathrm{~g}, 2 \mathrm{v}$ & & 1 & 0 & \\
\hline 4 & & 1 & 0 & \\
\hline $2 \mathrm{~g}, 2 \mathrm{v}$ & & 1 & 0 & \\
\hline 4 & & 1 & 0 & \\
\hline $2 \mathrm{v}, 3$ & & 1 & & 1 \\
\hline $2 \mathrm{v}$ & 0 & & 0 & \\
\hline $2 \mathrm{v}, 3$ & & 1 & 0 & \\
\hline 4 & & 1 & 0 & \\
\hline 3 & & 1 & 0 & \\
\hline $2 \mathrm{v}$ & 0 & & & 1 \\
\hline $2 \mathrm{v}$ & 0 & & & 1 \\
\hline $2 \mathrm{v}, 3$ & & 1 & & 1 \\
\hline $2 \mathrm{v}$ & 0 & & & 1 \\
\hline $2 \mathrm{v}, 3$ & & 1 & 0 & \\
\hline $2 \mathrm{v}, 2 \mathrm{~g}$ & & 1 & 0 & \\
\hline 4 & & 1 & 0 & \\
\hline $2 \mathrm{v}, 3$ & & 1 & & 1 \\
\hline $2 \mathrm{v}, 3$ & & 1 & 0 & \\
\hline $2 \mathrm{v}, 3$ & & 1 & 0 & \\
\hline $2 \mathrm{v}, 3$ & & 1 & 0 & \\
\hline $2 \mathrm{v}, 3$ & & 1 & 0 & \\
\hline 4 & & 1 & 0 & \\
\hline $2 \mathrm{v}, 3$ & & 1 & & 1 \\
\hline $2 \mathrm{v}$ & 0 & & 0 & \\
\hline $2 \mathrm{v}, 2 \mathrm{~g}$ & & 1 & & 1 \\
\hline $2 \mathrm{v}, 3$ & & 1 & 0 & \\
\hline $2 \mathrm{v}, 3$ & & 1 & & 1 \\
\hline $2 \mathrm{v}, 3$ & & 1 & 0 & \\
\hline
\end{tabular}




\begin{tabular}{|c|c|c|c|c|}
\hline Prompt & $\mathrm{De}$ & & $\mathrm{Cl}$ & \\
\hline $\begin{array}{l}2 \mathrm{v}, 3, \\
2 \mathrm{~g}\end{array}$ & & 1 & & 1 \\
\hline $2 \mathrm{v}$ & 0 & & 0 & \\
\hline $2 \mathrm{v}, 3$ & & 1 & & 1 \\
\hline $2 \mathrm{v}, 2 \mathrm{~g}$ & & 1 & & 1 \\
\hline $2 \mathrm{v}, 3$ & & 1 & 0 & \\
\hline $2 \mathrm{v}, 3$ & & 1 & & 1 \\
\hline $2 \mathrm{v}, 3$ & & 1 & 0 & \\
\hline $2 \mathrm{v}, 3$ & & 1 & 0 & \\
\hline $2 \mathrm{v}, 3$ & & 1 & & 1 \\
\hline $2 \mathrm{v}, 3$ & & 1 & & 1 \\
\hline $2 \mathrm{v}, 2 \mathrm{~g}$ & & 1 & & 1 \\
\hline $2 \mathrm{v}, 3$ & & 1 & 0 & \\
\hline $2 \mathrm{v}, 3$ & & 1 & 0 & \\
\hline $2 \mathrm{v}, 2 \mathrm{~g}$ & & 1 & & 1 \\
\hline $2 \mathrm{v}, 2 \mathrm{~g}$ & & 1 & & 1 \\
\hline $2 \mathrm{v}, 3$ & & 1 & 0 & \\
\hline $2 \mathrm{v}, 3$ & & 1 & & 1 \\
\hline $2 \mathrm{v}, 3$ & & 1 & 0 & \\
\hline $2 \mathrm{v}, 3$ & & 1 & & 1 \\
\hline $2 \mathrm{v}, 3$ & & 1 & 0 & . \\
\hline $2 \mathrm{v}, 1$ & 0 & & & 1 \\
\hline $2 \mathrm{v}, 3$ & & 1 & 0 & \\
\hline $2 \mathrm{v}$ & 0 & & & 1 \\
\hline $2 \mathrm{v}$ & 0 & & & 1 \\
\hline $2 \mathrm{v}, 2 \mathrm{~g}$ & & 1 & & 1 \\
\hline $2 \mathrm{v}, 2 \mathrm{~g}$ & & 1 & & 1 \\
\hline $2 \mathrm{v}$ & 0 & & 0 & \\
\hline $2 \mathrm{v}, 2 \mathrm{~g}$ & & 1 & & 1 \\
\hline $2 \mathrm{v}, 2 \mathrm{~g}$ & & 1 & & 1 \\
\hline $2 \mathrm{v}, 2 \mathrm{~g}$ & & 1 & & 1 \\
\hline $2 \mathrm{v}$ & 0 & & & 1 \\
\hline $2 \mathrm{v}$ & 0 & & & 1 \\
\hline $2 \mathrm{v}, 2 \mathrm{~g}$ & & 1 & & 1 \\
\hline $2 \mathrm{v}, 3$ & & 1 & 0 & \\
\hline $\begin{array}{l}2 \mathrm{v}, 2 \mathrm{~g}, \\
3\end{array}$ & & 1 & & 1 \\
\hline $\begin{array}{l}2 \mathrm{v}, 2 \mathrm{~g}, \\
3\end{array}$ & & 1 & & 1 \\
\hline
\end{tabular}




\begin{tabular}{|c|c|c|c|c|}
\hline Prompt & Der & & $\mathrm{Cl}$ & \\
\hline $2 \mathrm{v}, 2 \mathrm{~g}$ & & 1 & 0 & \\
\hline $2 \mathrm{v}, 2 \mathrm{~g}$ & & 1 & & 1 \\
\hline $\begin{array}{l}3,2 \mathrm{v}, \\
2 \mathrm{~g}\end{array}$ & & 1 & & 1 \\
\hline $2 \mathrm{v}$ & 0 & & 0 & \\
\hline $2 \mathrm{v}, 2 \mathrm{~g}$ & & 1 & & 1 \\
\hline $2 \mathrm{v}, 2 \mathrm{~g}$ & & 1 & & 1 \\
\hline $2 \mathrm{v}, 2 \mathrm{~g}$ & & 1 & & 1 \\
\hline $2 v$ & 0 & & & 1 \\
\hline $2 \mathrm{v}$ & 0 & & & 1 \\
\hline $\begin{array}{l}2 \mathrm{v}, 2 \mathrm{~g}, \\
3\end{array}$ & & 1 & & 1 \\
\hline $2 \mathrm{v}, 2 \mathrm{~g}$ & & 1 & & 1 \\
\hline $2 \mathrm{v}, 2 \mathrm{~g}, 3$ & & 1 & & 1 \\
\hline $2 \mathrm{v}$ & 0 & & & 1 \\
\hline $2 \mathrm{v}, 2 \mathrm{~g}$ & 0 & & & 1 \\
\hline $2 \mathrm{v}, 2 \mathrm{~g}$ & & 1 & & 1 \\
\hline $2 \mathrm{v}, 2 \mathrm{~g}$ & 0 & & & 1 \\
\hline $2 \mathrm{v}$ & 0 & & & 1 \\
\hline $2 \mathrm{v}, 2 \mathrm{~g}$ & 0 & & & 1 \\
\hline $2 \mathrm{v}, 2 \mathrm{~g}$ & 0 & & & 1 \\
\hline $2 \mathrm{v}, 2 \mathrm{~g}$ & & 1 & & 1 \\
\hline $2 \mathrm{v}, 2 \mathrm{~g}$ & 0 & & & 1 \\
\hline $2 \mathrm{v}, 2 \mathrm{~g}$ & & 1 & & 1 \\
\hline $\begin{array}{l}2 \mathrm{v}, 2 \mathrm{~g}, \\
3\end{array}$ & & 1 & & 1 \\
\hline $\begin{array}{l}2 \mathrm{v}, 2 \mathrm{~g}, \\
3\end{array}$ & & 1 & & 1 \\
\hline $2 \mathrm{v}, 2 \mathrm{~g}$ & 0 & & 0 & \\
\hline $2 \mathrm{v}, 2 \mathrm{~g}$ & 0 & & & 1 \\
\hline $2 \mathrm{v}$ & 0 & & 0 & \\
\hline $2 \mathrm{v}$ & 0 & & & 1 \\
\hline $2 \mathrm{v}, 2 \mathrm{~g}$ & & 1 & & 1 \\
\hline $2 \mathrm{v}, 2 \mathrm{~g}$ & & 1 & & 1 \\
\hline $2 \mathrm{v}, 2 \mathrm{~g}$ & & 1 & & 1 \\
\hline $2 \mathrm{v}, 2 \mathrm{~g}$ & & 1 & & 1 \\
\hline $2 \mathrm{v}, 2 \mathrm{~g}$ & & 1 & & 1 \\
\hline $2 \mathrm{v}, 2 \mathrm{~g}$ & & 1 & & 1 \\
\hline $2 \mathrm{v}, 2 \mathrm{~g}$ & & 1 & & 1 \\
\hline $2 \mathrm{v}, 2 \mathrm{~g}$ & & 1 & & 1 \\
\hline
\end{tabular}




\begin{tabular}{|c|c|c|c|c|}
\hline Prompt & De & & $\mathrm{Ch}$ & \\
\hline $2 \mathrm{v}, 2 \mathrm{~g}$ & & 1 & & 1 \\
\hline $2 \mathrm{~g}$ & & 1 & & 1 \\
\hline $2 \mathrm{v}, 2 \mathrm{~g}$ & & 1 & & 1 \\
\hline $2 \mathrm{v}, 2 \mathrm{~g}$ & 0 & & & 1 \\
\hline $2 \mathrm{v}, 2 \mathrm{~g}$ & & 1 & & 1 \\
\hline $2 \mathrm{v}, 2 \mathrm{~g}$ & & 1 & & 1 \\
\hline $2 \mathrm{v}$ & 0 & & & 1 \\
\hline $\begin{array}{l}2 \mathrm{v}, 2 \mathrm{~g}, \\
3\end{array}$ & & 1 & & 1 \\
\hline $\begin{array}{l}2 \mathrm{v}, 2 \mathrm{~g}, \\
3\end{array}$ & & 1 & & 1 \\
\hline $2 \mathrm{v}, 3$ & & 1 & & 1 \\
\hline $2 \mathrm{v}, 2 \mathrm{~g}$ & & 1 & & 1 \\
\hline $2 \mathrm{v}, 2 \mathrm{~g}$ & 0 & & & 1 \\
\hline $2 \mathrm{~g}, 3$ & & 1 & & 1 \\
\hline $2 \mathrm{t}$ & & 1 & & 1 \\
\hline $\begin{array}{l}2 \mathrm{v}, 3, \\
2 \mathrm{~g}\end{array}$ & & 1 & & 1 \\
\hline $2 \mathrm{v}, 3$ & & 1 & & 1 \\
\hline $2 \mathrm{v}, 3$ & & 1 & 0 & \\
\hline $2 \mathrm{v}, 3$ & & 1 & 0 & \\
\hline $\begin{array}{l}2 \mathrm{v}, 2 \mathrm{~g}, \\
3\end{array}$ & & 1 & & 1 \\
\hline $2 \mathrm{v}, 2 \mathrm{~g}$ & 0 & & & 1 \\
\hline $\begin{array}{l}2 \mathrm{v}, 3, \\
2 \mathrm{~g}\end{array}$ & & 1 & & 1 \\
\hline $2 \mathrm{v}, 3$ & & 1 & 0 & \\
\hline $2 \mathrm{v}, 3$ & & 1 & & 1 \\
\hline $2 \mathrm{v}, 3$ & & 1 & 0 & \\
\hline $2 \mathrm{v}, 2 \mathrm{~g}$ & 0 & & & 1 \\
\hline $\begin{array}{l}2 \mathrm{v}, 3, \\
2 \mathrm{~g}\end{array}$ & & 1 & & 1 \\
\hline 3 & & 1 & & 1 \\
\hline $2 \mathrm{v}, 3$ & & 1 & 0 & \\
\hline 3 & & 1 & 0 & \\
\hline $\begin{array}{l}2 \mathrm{v}, 2 \mathrm{t} \\
2 \mathrm{~g}\end{array}$ & & 1 & 0 & \\
\hline $2 \mathrm{v}, 2 \mathrm{~g}$ & 0 & & 0 & \\
\hline $2 \mathrm{v}, 2 \mathrm{~g}$ & & 1 & 0 & \\
\hline $2 \mathrm{v}, 2 \mathrm{t}$ & 0 & & 0 & \\
\hline $2 \mathrm{t}, 2 \mathrm{~g}$ & & 1 & & 1 \\
\hline
\end{tabular}




\begin{tabular}{|c|c|c|c|c|}
\hline Prompt & \multicolumn{2}{|c|}{ Device } & \multicolumn{2}{|c|}{ Child } \\
\hline $2 \mathrm{v}, 3$ & & 1 & 0 & \\
\hline $2 t$ & & 1 & 0 & \\
\hline 3 & & 1 & 0 & \\
\hline $2 \mathrm{v}, 2 \mathrm{~g}$ & & 1 & 0 & \\
\hline $2 \mathrm{~g}$ & & 1 & & 1 \\
\hline $2 \mathrm{v}$ & 0 & & 0 & \\
\hline $2 \mathrm{v}, 2 \mathrm{~g}$ & & 1 & & 1 \\
\hline $2 \mathrm{v}, 2 \mathrm{~g}$ & & 1 & & 1 \\
\hline $2 \mathrm{v}$ & 0 & & 0 & \\
\hline $2 \mathrm{v}, 2 \mathrm{~g}$ & & 1 & 0 & \\
\hline $2 \mathrm{v}, 3$ & & 1 & 0 & \\
\hline $2 \mathrm{v}, 2 \mathrm{t}$ & & 1 & & 1 \\
\hline $2 \mathrm{v}, 2 \mathrm{~g}$ & & 1 & 0 & \\
\hline $2 \mathrm{v}, 2 \mathrm{t}$ & & 1 & & 1 \\
\hline $2 \mathrm{v}$ & 0 & & & 1 \\
\hline $2 \mathrm{v}$ & 0 & & 0 & \\
\hline $2 \mathrm{v}, 2 \mathrm{~g}$ & & 1 & & 0 \\
\hline $2 \mathrm{t}, 2 \mathrm{v}$ & & 1 & 0 & \\
\hline $2 \mathrm{v}, 2 \mathrm{~g}$ & & 1 & & 1 \\
\hline $1,2 \mathrm{~g}$ & 0 & & 0 & \\
\hline $2 \mathrm{v}, 3$ & & 1 & 0 & \\
\hline $2 \mathrm{v}, 3$ & & 1 & 0 & \\
\hline $2 \mathrm{v}, 2 \mathrm{~g}$ & & 1 & 0 & \\
\hline 4 & & 1 & 0 & \\
\hline 4 & & 1 & 0 & \\
\hline $3,2 \mathrm{v}$ & & 1 & 0 & \\
\hline $2 \mathrm{v}, 2 \mathrm{~g}$ & & 1 & 0 & \\
\hline $2 \mathrm{v}, 2 \mathrm{~g}$ & & 1 & & 1 \\
\hline $3,2 \mathrm{v}$ & & 1 & 0 & \\
\hline $2 \mathrm{v}$ & 0 & & 0 & \\
\hline $2 \mathrm{v}, 2 \mathrm{~g}$ & & 1 & 0 & \\
\hline $2 \mathrm{v}, 2 \mathrm{t}$ & & 1 & 0 & \\
\hline $2 \mathrm{v}, 2 \mathrm{t}$ & & 1 & & 1 \\
\hline $2 \mathrm{v}, 3$ & & 1 & 0 & \\
\hline 1 & 0 & & & 1 \\
\hline $2 \mathrm{v}, 2 \mathrm{~g}$ & & 1 & 0 & \\
\hline 4 & & 1 & 0 & \\
\hline 1 & 0 & & & 1 \\
\hline $2 \mathrm{v}, 2 \mathrm{~g}$ & & 1 & 0 & \\
\hline
\end{tabular}




\begin{tabular}{|c|c|c|c|c|}
\hline Prompt & Der & & & \\
\hline 1 & 0 & & & 1 \\
\hline $2 \mathrm{v}, 2 \mathrm{~g}$ & & 1 & 0 & \\
\hline $2 \mathrm{v}, 2 \mathrm{t}$ & & 1 & 0 & \\
\hline $2 \mathrm{v}, 2 \mathrm{~g}$ & & 1 & 0 & \\
\hline 3 & & 1 & 0 & \\
\hline $2 \mathrm{v}, 1$ & 0 & & & 1 \\
\hline $2 \mathrm{v}, 1$ & 0 & & & 1 \\
\hline $2 \mathrm{v}, 2 \mathrm{~g}$ & 0 & & 0 & \\
\hline $2 \mathrm{v}, 2 \mathrm{~g}$ & & 1 & 0 & \\
\hline $\begin{array}{l}2 \mathrm{v}, 2 \mathrm{~g}, \\
3\end{array}$ & & 1 & 0 & \\
\hline $2 \mathrm{v}$ & 0 & & 0 & \\
\hline $2 \mathrm{~g}$ & 0 & & & 1 \\
\hline $3,2 \mathrm{~g}$ & & 1 & 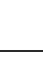 & 1 \\
\hline $2 \mathrm{v}, 3$ & & 1 & 0 & \\
\hline $2 \mathrm{~g}$ & 0 & & 0 & \\
\hline $2 \mathrm{v}, 3$ & & 1 & & 1 \\
\hline $2 \mathrm{v}$ & 0 & & 0 & \\
\hline $2 \mathrm{v}, 2 \mathrm{~g}$ & & 1 & 0 & \\
\hline $\begin{array}{l}2 \mathrm{v}, 3, \\
2 \mathrm{~g}\end{array}$ & & 1 & & 1 \\
\hline $2 \mathrm{v}$ & 0 & & 0 & \\
\hline $2 \mathrm{v}, 2 \mathrm{~g}$ & & 1 & 0 & \\
\hline $2 \mathrm{v}, 2 \mathrm{~g}$ & & 1 & & 1 \\
\hline $2 \mathrm{v}, 2 \mathrm{~g}$ & & 1 & & 1 \\
\hline $2 \mathrm{v}$ & 0 & & 0 & \\
\hline $\begin{array}{l}2 \mathrm{v}, 2 \mathrm{t} \\
2 \mathrm{~g}\end{array}$ & & 1 & 0 & \\
\hline $2 \mathrm{v}, 2 \mathrm{~g}$ & & 1 & 0 & \\
\hline $2 \mathrm{v}, 3$ & & 1 & 0 & \\
\hline $2 \mathrm{~g}$ & 0 & & & 1 \\
\hline $2 \mathrm{v}, 2 \mathrm{~g}$ & & 1 & 0 & \\
\hline $2 \mathrm{v}, 4$ & & 1 & 0 & \\
\hline $2 \mathrm{v}, 2 \mathrm{~g}$ & & 1 & 0 & \\
\hline $2 \mathrm{v}, 2 \mathrm{~g}$ & & 1 & 0 & \\
\hline $2 \mathrm{t}, 2 \mathrm{~g}$ & & 1 & & 1 \\
\hline $2 \mathrm{v}, 2 \mathrm{~g}$ & & 1 & & 1 \\
\hline $2 \mathrm{v}, 2 \mathrm{~g}$ & & 1 & & 1 \\
\hline $2 \mathrm{v}, 2 \mathrm{~g}$ & & 1 & & 1 \\
\hline $2 \mathrm{v}, 2 \mathrm{~g}$ & & 1 & 0 & \\
\hline
\end{tabular}




\begin{tabular}{|c|c|c|c|c|}
\hline Prompt & De & & & \\
\hline $2 \mathrm{v}, 2 \mathrm{~g}$ & & 1 & & 1 \\
\hline $2 \mathrm{v}$ & 0 & & & 1 \\
\hline $1,2 \mathrm{~g}$ & 0 & & & 1 \\
\hline $2 \mathrm{v}$ & 0 & & & 1 \\
\hline $2 \mathrm{v}, 3$ & & 1 & 0 & \\
\hline $2 \mathrm{v}, 2 \mathrm{~g}$ & & 1 & & 1 \\
\hline $2 \mathrm{v}, 2 \mathrm{~g}$ & & 1 & 0 & \\
\hline 4 & & 1 & 0 & \\
\hline $2 \mathrm{v}$ & 0 & & 0 & \\
\hline $2 \mathrm{v}, 2 \mathrm{~g}$ & 0 & & 0 & \\
\hline $2 \mathrm{v}, 2 \mathrm{~g}$ & & 1 & 0 & \\
\hline $2 \mathrm{v}, 3$ & & 1 & 0 & \\
\hline $2 \mathrm{v}, 3$ & & 1 & 0 & \\
\hline $2 \mathrm{v}, 2 \mathrm{~g}$ & & 1 & 0 & \\
\hline $2 \mathrm{v}, 2 \mathrm{~g}$ & & 1 & 0 & \\
\hline $2 \mathrm{v}, 3$ & & 1 & 0 & \\
\hline $2 \mathrm{~g}$ & & 1 & 0 & \\
\hline $2 \mathrm{v}, 2 \mathrm{t}$ & & 1 & & 1 \\
\hline $2 \mathrm{v}, 2 \mathrm{~g}$ & 0 & & 0 & \\
\hline $2 \mathrm{~g}, 2 \mathrm{v}$ & & 1 & 0 & \\
\hline $2 \mathrm{v}, 2 \mathrm{~g}$ & & 1 & 0 & \\
\hline $2 \mathrm{v}, 2 \mathrm{t}$ & & 1 & & 1 \\
\hline $2 \mathrm{v}$ & 0 & & 0 & \\
\hline $2 \mathrm{v}, 2 \mathrm{~g}$ & & 1 & & 1 \\
\hline $2 \mathrm{v}, 2 \mathrm{~g}$ & & 1 & & 1 \\
\hline $2 \mathrm{v}, 2 \mathrm{~g}$ & 0 & & & 1 \\
\hline $2 \mathrm{v}$ & 0 & & 0 & \\
\hline $2 \mathrm{v}, 2 \mathrm{~g}$ & & 1 & 0 & \\
\hline $2 \mathrm{v}, 3$ & & 1 & 0 & \\
\hline $2 \mathrm{v}, 2 \mathrm{~g}$ & 0 & & 0 & \\
\hline $2 \mathrm{v}, 2 \mathrm{~g}$ & & 1 & 0 & \\
\hline $2 \mathrm{v}, 3$ & & 1 & 0 & \\
\hline $2 \mathrm{v}, 2 \mathrm{~g}$ & & 1 & 0 & \\
\hline $2 \mathrm{v}, 3$ & & 1 & 0 & \\
\hline 3 & & 1 & 0 & \\
\hline $2 \mathrm{v}, 3$ & & 1 & 0 & \\
\hline $2 g$ & & 1 & 0 & \\
\hline $2 \mathrm{~g}$ & 0 & & & 1 \\
\hline $2 \mathrm{v}$ & 0 & & & 1 \\
\hline
\end{tabular}




\begin{tabular}{|c|c|c|c|c|}
\hline \multirow{2}{*}{$\frac{\text { Prompt }}{2 \mathrm{v}}$} & \multicolumn{2}{|c|}{ Device } & \multicolumn{2}{|c|}{ Child } \\
\hline & 0 & & & 1 \\
\hline 3 & & 1 & 0 & \\
\hline $2 \mathrm{v}$ & 0 & & 0 & \\
\hline $2 \mathrm{v}$ & 0 & & & 1 \\
\hline 4 & & 1 & 0 & \\
\hline $2 \mathrm{v}, 2 \mathrm{~g}$ & 0 & & & 1 \\
\hline $2 \mathrm{v}$ & 0 & & 0 & \\
\hline 4 & & 1 & 0 & \\
\hline $2 \mathrm{v}$ & 0 & & & 1 \\
\hline $2 \mathrm{v}, 4$ & & 1 & 0 & \\
\hline $2 \mathrm{v}, 4$ & & 1 & 0 & \\
\hline $2 \mathrm{v}$ & 0 & & & 1 \\
\hline 4 & & 1 & 0 & \\
\hline $2 \mathrm{v}, 2 \mathrm{t}$ & & 1 & & 1 \\
\hline $2 \mathrm{v}$ & 0 & & 0 & \\
\hline $2 \mathrm{v}, 2 \mathrm{~g}$ & 0 & & 0 & \\
\hline 1 & 0 & & 1 & \\
\hline $2 \mathrm{~g}, 1$ & 0 & & 0 & \\
\hline $2 \mathrm{v}$ & 0 & & & 1 \\
\hline 4 & & 1 & 0 & \\
\hline $2 \mathrm{~g}, 1$ & 0 & & & 1 \\
\hline $2 \mathrm{v}$ & 0 & & 0 & \\
\hline $2 \mathrm{v}, 3$ & & 1 & 0 & \\
\hline $2 \mathrm{~g}, 2 \mathrm{v}$ & & 1 & & 1 \\
\hline $2 \mathrm{v}$ & 0 & & 0 & \\
\hline $2 \mathrm{v}, 2 \mathrm{~g}$ & & 1 & 0 & \\
\hline $2 \mathrm{v}, 2 \mathrm{~g}$ & & 1 & 0 & \\
\hline 3 & & 1 & 0 & \\
\hline 4 & & 1 & 0 & \\
\hline $2 \mathrm{v}, 2 \mathrm{~g}$ & 0 & & & 1 \\
\hline 4 & & 1 & 0 & \\
\hline $2 \mathrm{v}, 2 \mathrm{~g}$ & & 1 & 0 & \\
\hline 3 & & 1 & 0 & \\
\hline 4 & & 1 & 0 & \\
\hline $2 \mathrm{v}$ & 0 & & 0 & \\
\hline $2 \mathrm{v}, 2 \mathrm{~g}$ & 0 & & 0 & \\
\hline 3 & & 1 & 0 & \\
\hline $2 \mathrm{v}$ & 0 & & 0 & \\
\hline $2 \mathrm{v}, 2 \mathrm{~g}$ & & 1 & 0 & \\
\hline
\end{tabular}




\begin{tabular}{|c|c|c|c|c|}
\hline Prompt & & & $\mathrm{Ch}$ & \\
\hline 3 & & 1 & 0 & \\
\hline 4 & & 1 & 0 & \\
\hline $2 \mathrm{v}, 2 \mathrm{t}$ & & 1 & 0 & \\
\hline $2 \mathrm{v}, 2 \mathrm{~g}$ & 0 & & 0 & \\
\hline $2 \mathrm{v}, 2 \mathrm{~g}$ & & 1 & 0 & \\
\hline 4 & & 1 & 0 & \\
\hline $1,2 \mathrm{~g}$ & 0 & & 0 & \\
\hline $2 \mathrm{v}, 2 \mathrm{t}$ & & 1 & 0 & \\
\hline 4 & & 1 & 0 & \\
\hline 4 & & 1 & 0 & \\
\hline $2 \mathrm{v}, 2 \mathrm{t}$ & & 1 & 0 & \\
\hline 4 & & 1 & 0 & \\
\hline $2 \mathrm{v}, 4$ & & 1 & 0 & \\
\hline $2 \mathrm{v}$ & 0 & & 0 & \\
\hline $2 \mathrm{v}, 2 \mathrm{~g}$ & 0 & & 0 & \\
\hline $\begin{array}{l}2 \mathrm{v}, 2 \mathrm{t}, \\
2 \mathrm{~g}\end{array}$ & & 1 & & 1 \\
\hline 4 & & 1 & 0 & \\
\hline $2 \mathrm{v}, 4$ & & 1 & 0 & \\
\hline $1,2 \mathrm{~g}$ & 0 & & 0 & \\
\hline $2 \mathrm{v}, 2 \mathrm{~g}$ & & 1 & 0 & \\
\hline 3 & & 1 & 0 & \\
\hline 4 & & 1 & 0 & \\
\hline 3 & & 1 & 0 & \\
\hline $2 \mathrm{v}, 4$ & & 1 & 0 & \\
\hline $2 \mathrm{v}, 4$ & & 1 & 0 & \\
\hline $2 \mathrm{v}, 2 \mathrm{~g}$ & 0 & & 0 & \\
\hline $2 \mathrm{v}, 2 \mathrm{~g}$ & & 1 & 0 & \\
\hline $2 \mathrm{v}$ & 0 & & 0 & \\
\hline 3 & & 1 & 0 & \\
\hline $2 v$ & 0 & & 0 & \\
\hline $2 \mathrm{v}, 2 \mathrm{~g}$ & & 1 & 0 & \\
\hline $3,2 \mathrm{v}$ & & 1 & 0 & \\
\hline $2 \mathrm{v}$ & 0 & & 0 & \\
\hline 4 & & 1 & 0 & \\
\hline $2 \mathrm{v}, 4$ & & 1 & 0 & \\
\hline $2 \mathrm{v}$ & 0 & & & 1 \\
\hline 4 & & 1 & 0 & \\
\hline $2 \mathrm{v}, 3$ & & 1 & 0 & \\
\hline
\end{tabular}




\begin{tabular}{|c|c|c|c|c|}
\hline \multirow{2}{*}{$\frac{\text { Prompt }}{2 \mathrm{v}}$} & \multicolumn{2}{|c|}{ Device } & \multicolumn{2}{|c|}{ Child } \\
\hline & 0 & & 0 & \\
\hline $2 \mathrm{v}, 2 \mathrm{~g}$ & & 1 & 0 & \\
\hline 3 & & 1 & & 1 \\
\hline 4 & & 1 & 0 & \\
\hline $2 \mathrm{v}$ & 0 & & 0 & \\
\hline 3 & & 1 & & 1 \\
\hline 4 & & 1 & 0 & \\
\hline 4 & & 1 & 0 & \\
\hline 4 & & 1 & 0 & \\
\hline $2 \mathrm{v}$ & 0 & & 0 & \\
\hline $2 \mathrm{v}, 3$ & & 1 & & 1 \\
\hline 4 & & 1 & 0 & \\
\hline 1 & 0 & & 0 & \\
\hline $2 \mathrm{v}$ & 0 & & 0 & \\
\hline $2 \mathrm{v}, 3$ & & 1 & 0 & \\
\hline $2 \mathrm{v}$ & 0 & & 0 & \\
\hline $2 \mathrm{v}$ & 0 & & 0 & \\
\hline $2 \mathrm{v}$ & 0 & & 0 & \\
\hline $2 \mathrm{v}$ & 0 & & 0 & \\
\hline $2 \mathrm{v}$ & 0 & & 0 & \\
\hline $2 \mathrm{v}, 2 \mathrm{~g}$ & & 1 & 0 & \\
\hline $2 \mathrm{v}$ & 0 & & 0 & \\
\hline 3 & & 1 & & 1 \\
\hline 4 & & 1 & 0 & \\
\hline $2 \mathrm{v}, 4$ & & 1 & 0 & \\
\hline 4 & & 1 & 0 & \\
\hline $2 \mathrm{v}, 2 \mathrm{~g}$ & 0 & & 0 & \\
\hline $2 \mathrm{v}$ & 0 & & 0 & \\
\hline 3 & & 1 & 0 & \\
\hline $2 \mathrm{v}, 2 \mathrm{~g}$ & 0 & & 0 & \\
\hline $2 \mathrm{v}, 2 \mathrm{~g}$ & & 1 & 0 & \\
\hline $2 \mathrm{v}$ & 0 & & 0 & \\
\hline $2 \mathrm{v}, 2 \mathrm{~g}$ & 0 & & & 1 \\
\hline $2 \mathrm{v}, 2 \mathrm{~g}$ & & 1 & . & 1 \\
\hline $2 \mathrm{v}$ & 0 & & 0 & \\
\hline $2 \mathrm{v}, 3$ & & 1 & 0 & \\
\hline $2 \mathrm{v}, 2 \mathrm{~g}$ & 0 & & & 1 \\
\hline $2 \mathrm{v}, 3$ & & 1 & & 1 \\
\hline 1 & 0 & & 0 & \\
\hline
\end{tabular}




\begin{tabular}{|c|c|c|c|c|}
\hline Prompt & Der & & $\mathrm{Ch}$ & nild \\
\hline $2 \mathrm{v}, 2 \mathrm{~g}$ & & 1 & 0 & \\
\hline $2 \mathrm{v}$ & 0 & & 0 & \\
\hline $2 \mathrm{v}, 3$ & & 1 & 0 & \\
\hline $2 \mathrm{~g}$ & 0 & & 0 & \\
\hline 4 & & 1 & 0 & \\
\hline $2 \mathrm{v}$ & 0 & & 0 & \\
\hline $2 \mathrm{v}, 2 \mathrm{~g}$ & 0 & & 0 & \\
\hline $2 \mathrm{v}, 2 \mathrm{~g}$ & & 1 & 0 & \\
\hline $2 \mathrm{v}$ & 0 & & 0 & \\
\hline $2 \mathrm{t}, 2 \mathrm{v}$ & 0 & & 0 & \\
\hline $2 \mathrm{v}, 3$ & & 1 & 0 & \\
\hline $2 \mathrm{v}, 3$ & & 1 & 0 & \\
\hline $\begin{array}{l}2 \mathrm{v}, 2 \mathrm{~g} \\
4\end{array}$ & & 1 & 0 & \\
\hline $2 \mathrm{v}, 4$ & & 1 & 0 & \\
\hline $2 \mathrm{v}, 3$ & & 1 & 0 & \\
\hline $2 \mathrm{v}, 2 \mathrm{~g}$ & 0 & & 0 & \\
\hline $2 \mathrm{v}, 3$ & & 1 & 0 & \\
\hline $2 \mathrm{v}, 2 \mathrm{~g}$ & & 1 & 0 & \\
\hline $2 \mathrm{v}, 3$ & & 1 & 0 & \\
\hline $2 \mathrm{v}, 3$ & & 1 & 0 & \\
\hline $2 \mathrm{v}, 3$ & & 1 & 0 & \\
\hline $2 \mathrm{v}, 3$ & & 1 & 0 & \\
\hline $2 \mathrm{v}$ & 0 & & 0 & \\
\hline $2 \mathrm{v}, 3$ & & 1 & 0 & \\
\hline $2 \mathrm{v}, 3$ & 1 & & 1 & \\
\hline 4 & & 1 & 0 & \\
\hline $2 \mathrm{v}$ & 0 & & 0 & \\
\hline $2 \mathrm{v}, 3$ & & 1 & 0 & \\
\hline $2 \mathrm{v}, 3$ & & 1 & 0 & \\
\hline $2 \mathrm{v}, 3$ & & 1 & 0 & \\
\hline $2 \mathrm{v}, 3$ & & 1 & 0 & \\
\hline $2 \mathrm{v}, 3$ & & 1 & 0 & \\
\hline $2 \mathrm{v}, 4$ & & 1 & 0 & \\
\hline $2 \mathrm{v}, 4$ & & 1 & 0 & \\
\hline $2 \mathrm{v}, 2 \mathrm{~g}$ & 0 & & 0 & \\
\hline 4 & & 1 & 0 & \\
\hline $2 \mathrm{v}, 4$ & & 1 & 0 & \\
\hline $2 \mathrm{v}$ & 0 & & 0 & \\
\hline
\end{tabular}




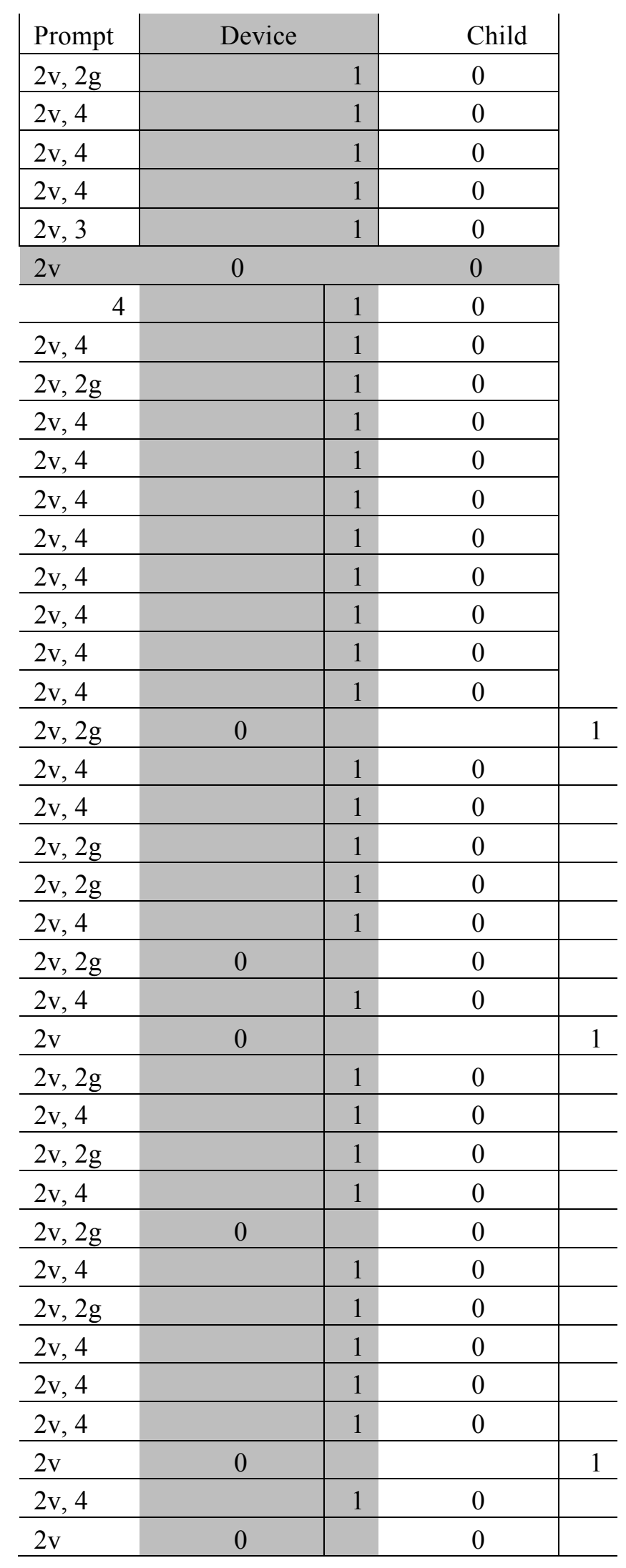




\begin{tabular}{|c|c|c|c|c|}
\hline Prompt & De & & & \\
\hline $2 \mathrm{v}, 4$ & & 1 & 0 & \\
\hline $2 \mathrm{v}$ & 0 & & 0 & \\
\hline 4 & & 1 & 0 & \\
\hline $2 \mathrm{~V}$ & 0 & & 0 & \\
\hline $2 \mathrm{v}$ & 0 & & 0 & \\
\hline $2 \mathrm{v}, 2 \mathrm{~g}$ & & 1 & & 1 \\
\hline $2 \mathrm{v}, 3$ & & 1 & 0 & \\
\hline $2 \mathrm{v}, 2 \mathrm{~g}$ & & 1 & 0 & \\
\hline $2 \mathrm{v}, 3$ & & 1 & 0 & \\
\hline 4 & & 1 & 0 & \\
\hline $2 \mathrm{~V}$ & 0 & & 0 & \\
\hline $2 \mathrm{v}, 2 \mathrm{~g}$ & 0 & & 0 & \\
\hline 4 & & 1 & 0 & \\
\hline $2 \mathrm{v}, 2 \mathrm{~g}$ & 0 & & 0 & \\
\hline 4 & & 1 & 0 & \\
\hline $2 \mathrm{v}, 2 \mathrm{~g}$ & 0 & & & 1 \\
\hline 4 & & 1 & 0 & \\
\hline $2 \mathrm{v}, 4$ & & 1 & 0 & \\
\hline $2 \mathrm{v}, 2 \mathrm{~g}$ & & 1 & 0 & \\
\hline $2 \mathrm{v}, 4$ & & 1 & 0 & \\
\hline $2 g, 1$ & 0 & & 0 & \\
\hline $2 \mathrm{v}$ & 0 & & 0 & \\
\hline 4 & & 1 & 0 & \\
\hline $2 \mathrm{v}$ & 0 & & 0 & \\
\hline $2 \mathrm{v}, 4$ & & 1 & 0 & \\
\hline $2 \mathrm{v}$ & 0 & & & 1 \\
\hline $2 \mathrm{v}, 4$ & & 1 & 0 & \\
\hline $2 \mathrm{v}, 2 \mathrm{~g}$ & 0 & & 0 & \\
\hline 4 & & 1 & 0 & \\
\hline $2 \mathrm{v}$ & 0 & & 0 & \\
\hline $2 \mathrm{v}, 2 \mathrm{~g}$ & 0 & & 0 & \\
\hline $2 \mathrm{v}, 3$ & & 1 & 0 & \\
\hline $2 \mathrm{v}, 3$ & & 1 & 0 & \\
\hline $2 \mathrm{v}, 2 \mathrm{~g}$ & & 1 & 0 & \\
\hline 4 & & 1 & 0 & \\
\hline $2 \mathrm{v}, 2 \mathrm{~g}$ & 0 & & 0 & \\
\hline 4 & & 1 & 0 & \\
\hline $2 \mathrm{v}$ & 0 & & 0 & \\
\hline $2 \mathrm{v}, 2 \mathrm{~g}$ & & 1 & & 1 \\
\hline
\end{tabular}




\begin{tabular}{|c|c|c|c|c|}
\hline \multirow{2}{*}{$\begin{array}{r}\text { Prompt } \\
4\end{array}$} & \multicolumn{2}{|c|}{ Device } & \multicolumn{2}{|c|}{ Child } \\
\hline & & 1 & 0 & \\
\hline $2 \mathrm{v}, 2 \mathrm{~g}$ & & 1 & 0 & \\
\hline $2 \mathrm{v}, 3$ & & 1 & 0 & \\
\hline $2 \mathrm{v}, 3$ & & 1 & 0 & \\
\hline $2 \mathrm{v}, 3$ & & 1 & 0 & \\
\hline 4 & & 1 & 0 & \\
\hline $2 \mathrm{v}, 2 \mathrm{~g}$ & 0 & & 0 & \\
\hline $2 \mathrm{v}, 2 \mathrm{~g}$ & 0 & & 0 & \\
\hline $2 \mathrm{v}, 3$ & & 1 & 0 & \\
\hline 4 & & 1 & 0 & \\
\hline $2 \mathrm{v}, 2 \mathrm{~g}$ & & 1 & 0 & \\
\hline 4 & & 1 & 0 & \\
\hline $2 \mathrm{v}, 2 \mathrm{~g}$ & & 1 & & 1 \\
\hline 4 & & 1 & 0 & \\
\hline $2 \mathrm{v}, 2 \mathrm{~g}$ & 0 & & 0 & \\
\hline $2 \mathrm{v}, 3$ & & 1 & 0 & \\
\hline 4 & & 1 & 0 & \\
\hline $2 \mathrm{v}, 2 \mathrm{~g}$ & & 1 & 0 & \\
\hline $2 \mathrm{v}, 2 \mathrm{~g}$ & & 1 & 0 & \\
\hline 4 & & 1 & 0 & \\
\hline $2 \mathrm{v}, 3$ & & 1 & 0 & \\
\hline 4 & & 1 & 0 & \\
\hline
\end{tabular}

